\title{
Article \\ Preparation of Silk Fibroin/Carboxymethyl Chitosan Hydrogel under Low Voltage as a Wound Dressing
}

\author{
Zhenyu Chen $\mathbb{D}$, Xiaoning Zhang * $\mathbb{D}$, Jianwei Liang, Yansong Ji, Yuqing Zhou and Hao Fang \\ State Key Laboratory of Silkworm Genome Biology, College of Sericulture, Textile and Biomass Sciences, \\ Southwest University, Chongqing 400715, China; c618@email.swu.edu.cn (Z.C.); liangjw@email.swu.edu.cn (J.L.); \\ jys2020@email.swu.edu.cn (Y.J.); zhouxguai@163.com (Y.Z.); fangritian@email.swu.edu.cn (H.F.) \\ * Correspondence: xzhang@swu.edu.cn; Tel.: +86-15922815612
}

Citation: Chen, Z.; Zhang, X.; Liang,

J.; Ji, Y.; Zhou, Y.; Fang, H.

Preparation of Silk

Fibroin/Carboxymethyl Chitosan Hydrogel under Low Voltage as a Wound Dressing. Int. J. Mol. Sci. 2021, 22, 7610. https://doi.org/10.3390/ ijms22147610

Academic Editor: Marcel Popa

Received: 23 May 2021

Accepted: 13 July 2021

Published: 16 July 2021

Publisher's Note: MDPI stays neutral with regard to jurisdictional claims in published maps and institutional affiliations.

Copyright: (c) 2021 by the authors. Licensee MDPI, Basel, Switzerland. This article is an open access article distributed under the terms and conditions of the Creative Commons Attribution (CC BY) license (https:// creativecommons.org/licenses/by/ $4.0 /)$.

\begin{abstract}
At present, silk fibroin (SF) hydrogel can be prepared by means of electrodeposition at $25 \mathrm{~V}$ in direct current (DC) mode. Reducing the applied voltage would provide benefits, including lower fabrication costs, less risk of high voltage shocks, and better stability of devices. Here, a simple but uncommon strategy for SF-based hydrogel preparation using $4 \mathrm{~V}$ in DC mode is discussed. SF was mixed and cross-linked with carboxymethyl chitosan (CMCS) through hydrogen bonding, then co-deposited on the graphite electrode. The thickness, mass, and shape of the SF/CMCS hydrogel were easily controlled by adjusting the electrodeposition parameters. Morphological characterization of the prepared hydrogel via SEM revealed a porous network within the fabricated hydrogel. This structure was due to intermolecular hydrogen bonding between SF and CMCS, according to the results of thermogravimetric analysis and rheological measurements. As a potential wound dressing, SF/CMCS hydrogel maintained a suitable moisture environment for wound healing and demonstrated distinct properties in terms of promoting the proliferation of HEK-293 cells and antibacterial activity against Escherichia coli and Staphylococcus aureus. Furthermore, histological studies were conducted on a full-thickness skin wound in rats covered with the SF/CMCS hydrogel, with results indicating that this hydrogel can promote wound re-epithelization and enhance granulation tissue formation. These results illustrate the feasibility of using the developed strategy for SF-based hydrogel fabrication in practice for wound dressing.
\end{abstract}

Keywords: silk fibroin; carboxymethyl chitosan; electrodeposition; wound dressing

\section{Introduction}

Silk fibroin (SF) is the major protein in the silk produced by Bombyx mori. After degumming, silk fibroin fiber can be dissolved in a highly concentrated salt solution [1]. This solution is called regenerated silk fibroin (RSF) solution once it is desalinated. RSF is characterized by a slow biodegradation rate, suitable cellular response, and high biocompatibility [2]. In addition, RSF can be reconstituted in various forms [3-6]. Among these forms, SF-based hydrogel is particularly attractive as it can provide a three-dimensional structure, has a high water content, soft consistency, and excellent water stability, and can closely adhere to the skin [7]. SF-based hydrogel can be prepared through the addition of a chemical cross-linking agent [8], sonication [9], or application of an electric current [10]. The use of a chemical cross-linking agent reduces the biocompatibility of the hydrogel [8], whereas sonication-induced gelation suffers from slow gel formation and an unstable structure [11]. SF-based hydrogel prepared via electrogelation is free from chemical cross-linking agents and can be achieved over a short and controllable period [12]. At present, SF electrogelation can be obtained within 5 min under a $25 \mathrm{~V}$ direct current (DC) voltage $[10,13]$. Reducing the driving voltage of SF electrogelation can save energy, avoid potential electrochemical reactions when working with high voltages, and lower the fabrication cost for an electrogelation device, which should decrease the fabrication cost and increase product stability. 
Carboxymethyl chitosan (CMCS) is a chitosan (the second most abundant polysaccharide in nature [14]) derivative with properties including biocompatibility, antibacterial activity, and moisture retention. In addition, it can participate in free radical scavenging as an antioxidant [14]. Wang et al. fabricated a carboxylated chitosan-derived film based on coordinated electrodeposition [15], in which the silver electrode underwent anodic electrochemical oxidation and then generated $\mathrm{Ag}^{+}$ions in situ. These in situ-generated $\mathrm{Ag}^{+}$ions can coordinate with the carboxylated chitosan adjacent to the silver electrode (carboxylated chitosan has abundant $-\mathrm{COOH},-\mathrm{NH}_{2}$, and $-\mathrm{OH}$ groups) and generate a composite film that can be peeled from the silver electrode [16]. Because the $\mathrm{Ag}^{+}$ions are released near the electrode surface, the thickness of the fabricated composite film was limited within the micrometer scale. In addition, carboxylated chitosan-derived film was prepared with the aid of metal ions, which are potentially biotoxic.

It was reported that chitosan can self-associate to form a three-dimensional hydrogel network via a cathodic neutralization mechanism [17]. The chitosan molecules carry positive charges through the protonation of amine groups in an acidic aqueous environment and are attracted to the cathode surface by electrostatic attraction. Subsequently, positively charged chitosan molecules are neutralized by hydroxide ions generated on the cathode surface, which are then deposited and undergo self-association to form the hydrogel $[18,19]$. Upon deprotonation of the carboxyl groups, CMCS would carry a negative charge in an alkaline solution [20]. We therefore believe that the fabrication of CMCS hydrogel, without the involvement of metal ions, by means of electrodeposition following an anodic neutralization mechanism is achievable. In addition, it has been suggested that the carboxyl and amino groups of CMCS can form hydrogen bonds with SF molecules [21]. We hypothesized that SF can cross-link with CMCS via hydrogen bonds and then electrodeposit along with CMCS on the anode to form a composite hydrogel (see Graphical Abstract).

Due to the high capacity of hydrogels for the absorption of physiological exudates from wounds and their capability to provide the wound area with a moisture balance that can enhance wound healing, hydrogels have been received increasing attention in the field of wound care $[7,22,23]$. Considering the intrinsic properties of both SF and CMCS as mentioned earlier, we believe a SF/CMCS composite hydrogel may exhibit a promising potential for use as a wound dressing.

In this work, we aimed to fabricate an SF-based hydrogel under low-driving voltage by exploiting the electrogelation process of CMCS and the interactions between SF and CMCS molecules in solution. The introduced strategy for SF-based hydrogel preparation does not require any additives (such as metal ions) and allows for a precisely controlled and tunable thickness, which breaks the micrometer scale limitation encountered in previous works. Subsequently, the cytotoxicity and the wound healing potential of the prepared hydrogel were investigated. It should be noted that no comprehensive work was dedicated to assess the effectiveness of the SF/CMCS composite as a wound healing agent at present.

\section{Results}

Here, an SF/CMCS hydrogel, prepared from a solution containing 5\% SF and 2\% CMCS under a voltage of $4 \mathrm{~V}$ in DC mode, was selected (the detailed explanation can be found in Section 1 of the Supplementary Materials, Figures S1-S5). The prepared hydrogel can be easily detached from the surface of the anode and independently used as a wound dressing to implement the subsequent characterization and evaluation. No hydrogel deposition was observed on the surface of the cathode or on the reference electrode.

\subsection{Preparation of the SF/CMCS and CMCS Hydrogels}

Figure 1a-h shows cloudy white hydrogels prepared from 2\% CMCS solution, and Figure 1i-p shows milky white hydrogels fabricated from a 5\% SF and 2\% CMCS mixture under a DC voltage of $4 \mathrm{~V}$ for different durations. All hydrogels exhibit a smooth and homogeneous surface, and their thickness increased with increasing the electrodeposition time. In addition, all the SF/CMCS hydrogels exhibit greater thickness than that of CMCS 
hydrogel. It should be noted that no silver ion leakage from the $\mathrm{Ag} / \mathrm{AgCl}$ reference electrode was detected during the electrodeposition process (Supplementary Materials Section 2).
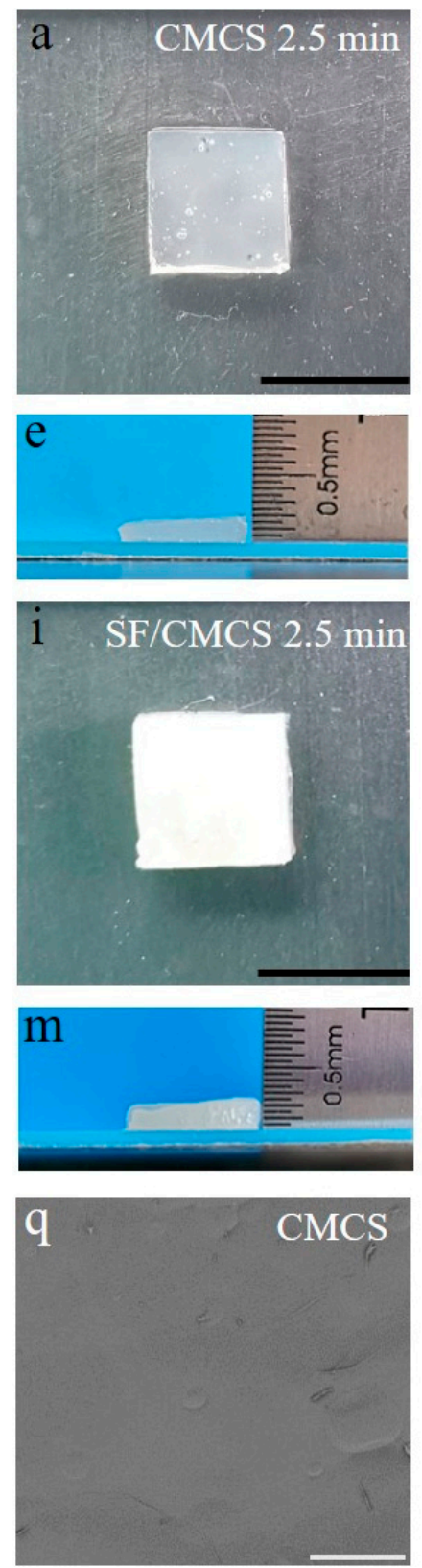
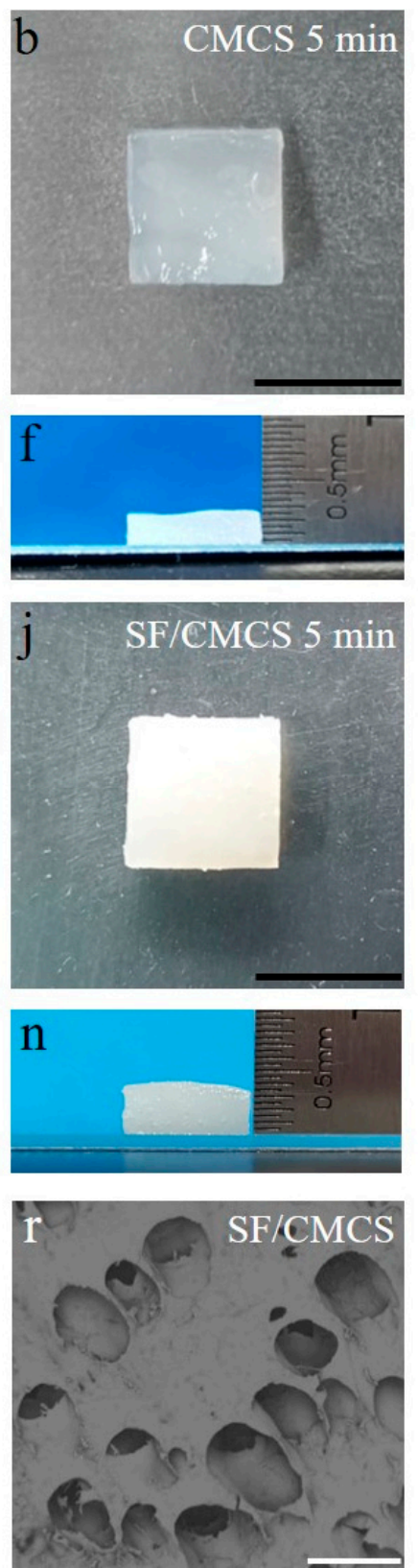
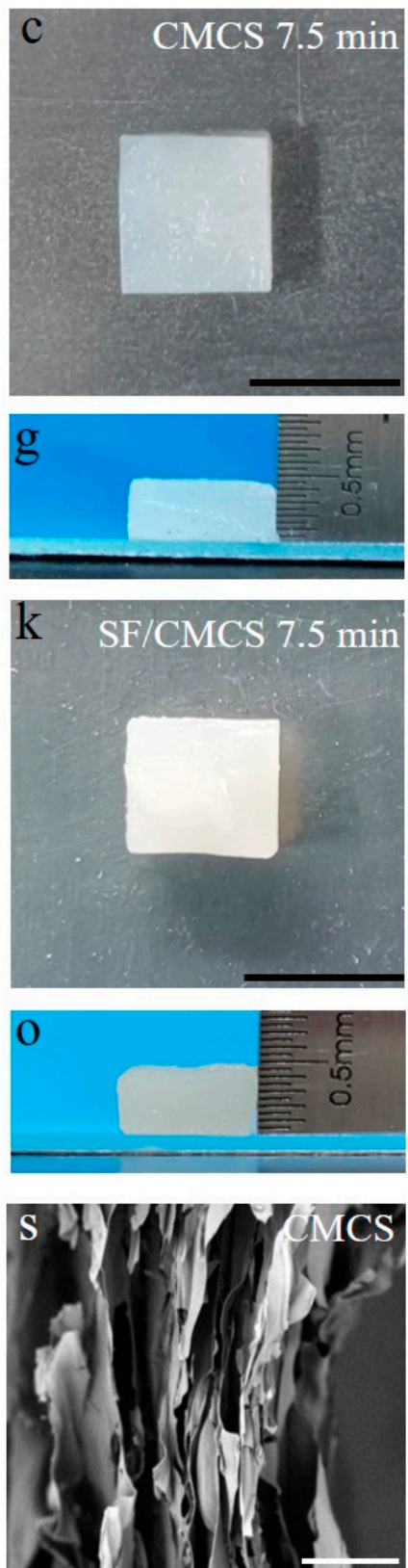
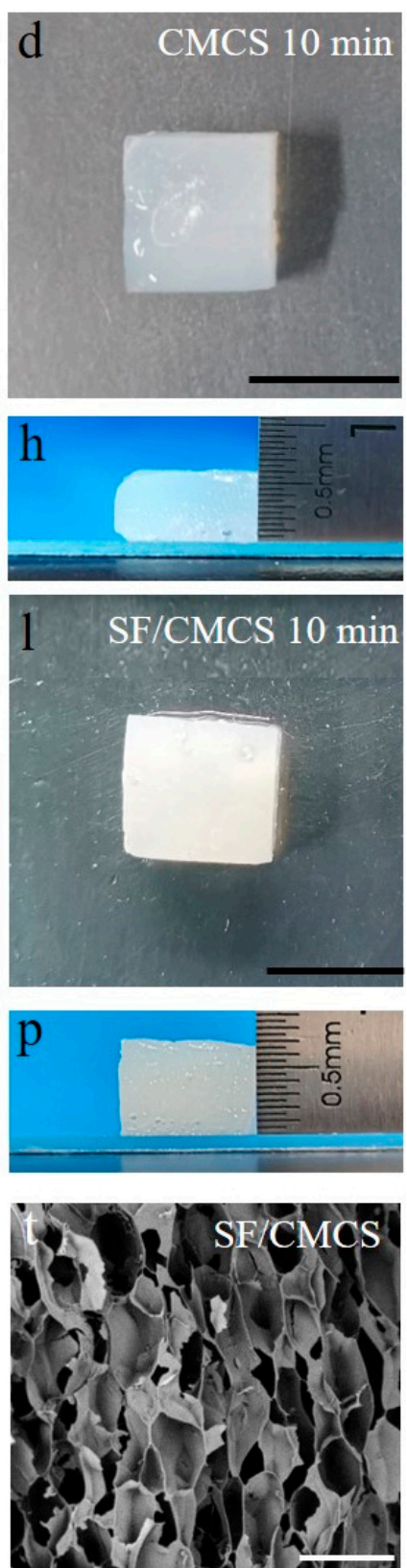

Figure 1. Photographs of the CMCS hydrogels prepared from $2 \%$ CMCS solution and the SF/CMCS hydrogels prepared from a 5\% SF and 2\% CMCS mixture with a DC voltage of $4 \mathrm{~V}$ applied for $2.5 \mathrm{~min}(\mathbf{a}, \mathbf{l}), 5.0 \mathrm{~min}(\mathbf{b}, \mathbf{j}), 7.5 \mathrm{~min}(\mathbf{c}, \mathbf{k})$, and $10 \mathrm{~min}(\mathbf{d}, \mathbf{p}) .(\mathbf{e}-\mathbf{h}, \mathbf{m}-\mathbf{p})$ are the corresponding side-view images of $(\mathbf{a}-\mathbf{d}, \mathbf{i}-\mathbf{l})$, respectively (scale bar: $1 \mathrm{~cm})$. $(\mathbf{q}, \mathbf{r})$ present the SEM images of the top surface morphology of freeze-dried CMCS hydrogel and SF/CMCS hydrogel, respectively. $(\mathbf{s}, \mathbf{t})$ exhibit the cross-sectional SEM images of CMCS and SF/CMCS hydrogels, respectively (scale bar: $200 \mu \mathrm{m}$ ).

The microstructures of freeze-dried CMCS hydrogel and SF/CMCS hydrogel were investigated using a scanning electron microscope (SEM). The surface of the prepared CMCS hydrogel was obviously smooth and uniform, without a porous structure (Figure 1q), whereas SF/CMCS hydrogels demonstrated a porous surface morphology (Figure 1r). The SEM cross-sectional images for the freeze-dried CMCS hydrogels and SF/CMCS hydrogels are shown in Figure 1s,t. CMCS hydrogel was found to consist of close packed layers; this layered structure was also observed in the electrodeposition of chitosan hydrogel from 
previous studies [24]. SF/CMCS hydrogel demonstrates a cross-linking hierarchical porous architecture, with an average pore diameter of $98.27 \pm 17.45 \mu \mathrm{m}$ (Table S1), determined from SEM images using the analysis tool in ImageJ software (National Institutes of Health, Bethesda, MD, USA).

According to the approach described in the Materials and Methods section, $65.2 \% \pm$ $13.9 \%$ of SF protein was present in the SF/CMCS hydrogel, which indicates that SF was the main component of the SF/CMCS hydrogel. The cumulative release of SF over time was measured by immersing the SF/CMCS hydrogel in deionized water. Then, the amount of protein released was determined through a Bradford protein assay. In the first $6 \mathrm{~h}$, only a negligible amount of SF (approximately $0.374 \%$, Table 1 ) was released, confirming the efficient cross-linking of SF and CMCS molecules.

Table 1. The mass percentage of cumulative SF released from the SF/CMCS hydrogel over time.

\begin{tabular}{cccccc}
\hline Time & $\mathbf{1 0} \mathbf{~} \mathbf{m i n}$ & $\mathbf{3 0} \mathbf{~} \mathbf{~ i n}$ & $\mathbf{1 ~ h}$ & $\mathbf{3 ~ h}$ & $\mathbf{6 ~ h}$ \\
\hline Percentage (\%) & $0.295 \pm 0.023$ & $0.322 \pm 0.010$ & $0.325 \pm 0.006$ & $0.352 \pm 0.010$ & $0.374 \pm 0.022$ \\
\hline
\end{tabular}

Figure 2 shows that a hydrogel film with tailored shapes was then prepared by patterning the surface of the graphite electrode through an insulating block layer. This demonstration reveals that the reported approach allows a programmable and controllable means for assembling an SF-based hydrogel with spatial selectivity.
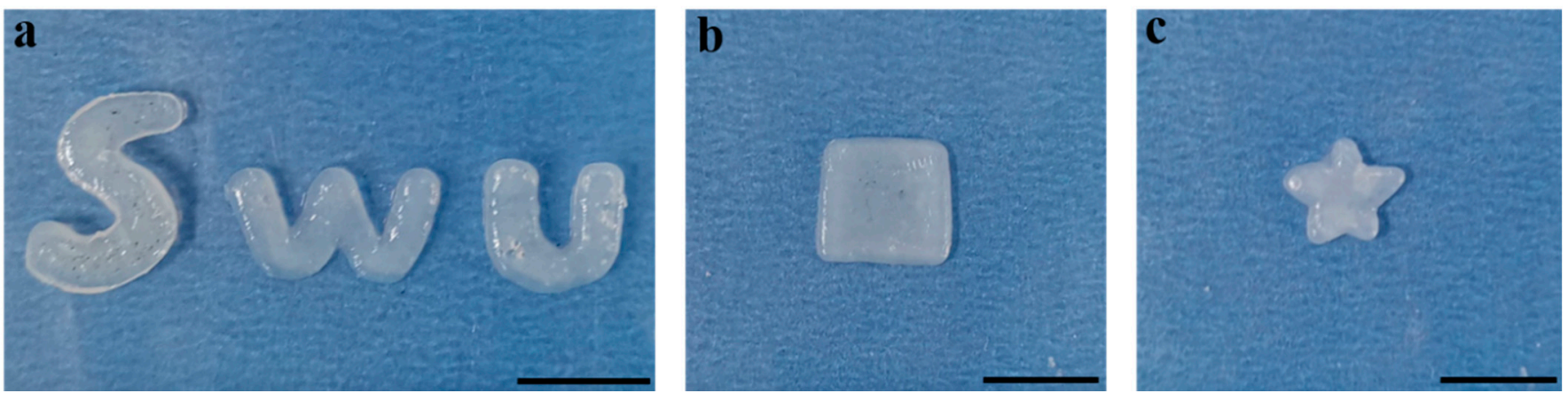

Figure 2. Photographs of the SF/CMCS hydrogel film with different shapes: (a) "SWU” logo, (b) square, and (c) pentagram (scale bar: $1 \mathrm{~cm}$ ).

\subsection{Rheological Measurements}

Rheological measurements were performed on the polymer solutions to assess the behaviors of SF and CMCS before and after they were mixed together. Figure 3 shows that the viscosity of the $10 \% \mathrm{SF}$ solution was $7.70 \pm 0.04 \mathrm{mpa} \cdot \mathrm{s}$, and the viscosity of the $4 \%$ CMCS solution was $51.77 \pm 0.09 \mathrm{mpa} \cdot \mathrm{s}$. The viscosity increased to $25.85 \pm 0.13 \mathrm{mpa} \cdot \mathrm{s}$ upon mixing the SF and CMCS solutions together while maintaining a composition of $5 \%$ $\mathrm{SF}$ and $2 \% \mathrm{CMCS}$ in the mixture.

\subsection{Mechanical Properties and Infrared Spectroscopy (FTIR) of the SF/CMCS Hydrogel}

The compressive properties of the prepared CMCS and SF/CMCS hydrogels were measured as shown in Figure 4a. According to Figure 4a, the compressive modulus and stress of the SF/CMCS hydrogel were significantly improved compared with those of the CMCS hydrogel. 


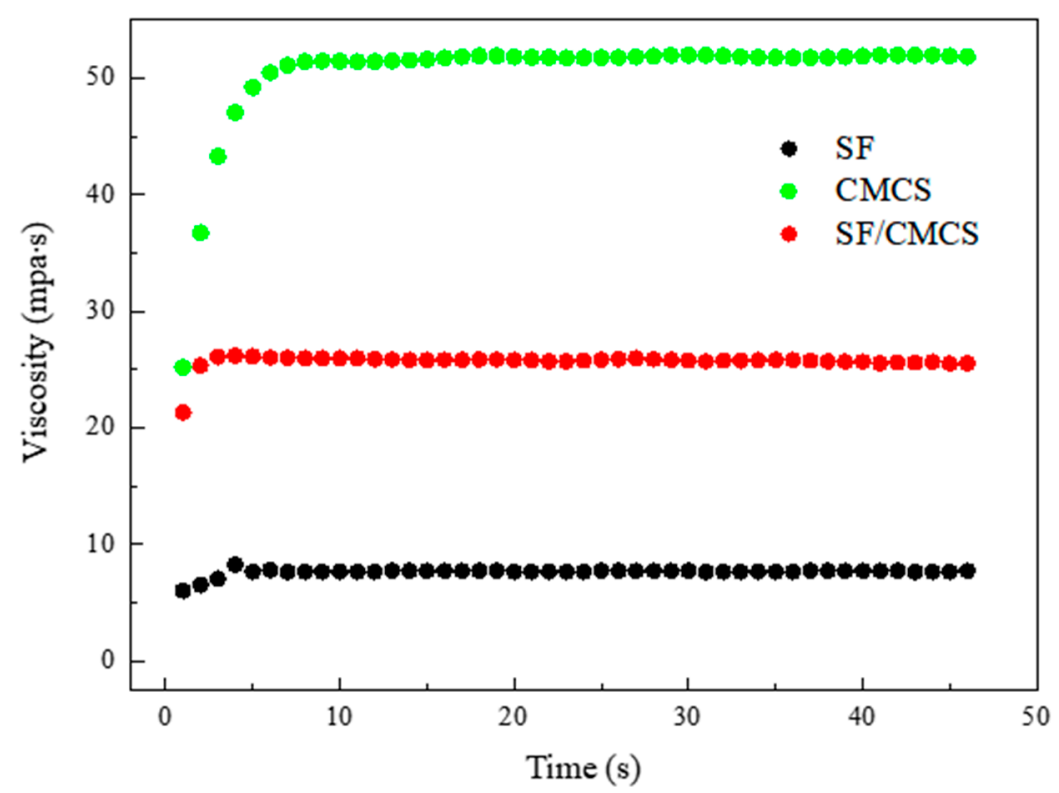

Figure 3. Viscosity-time curves of the SF solution, CMCS solution, and SF/CMCS mixture.

a

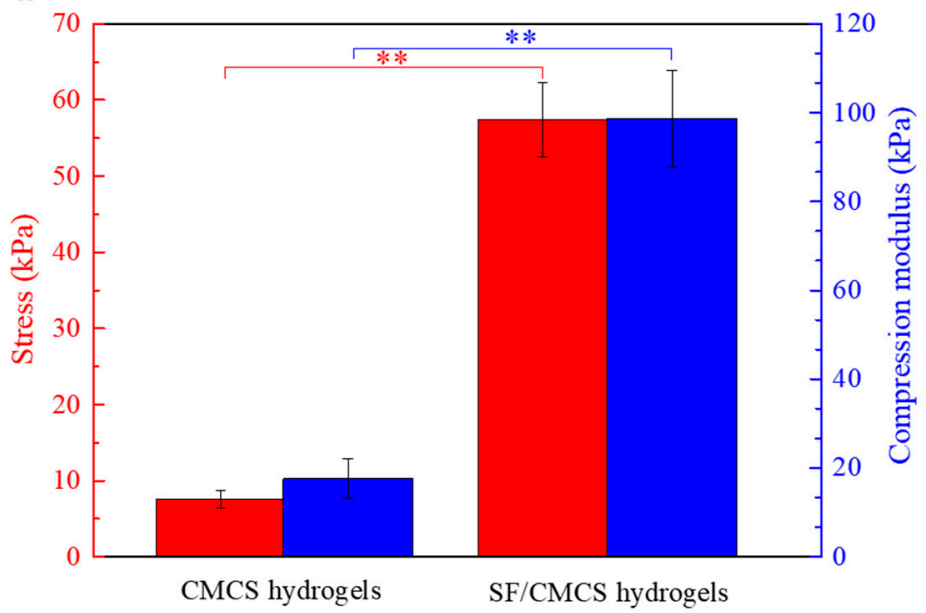

b

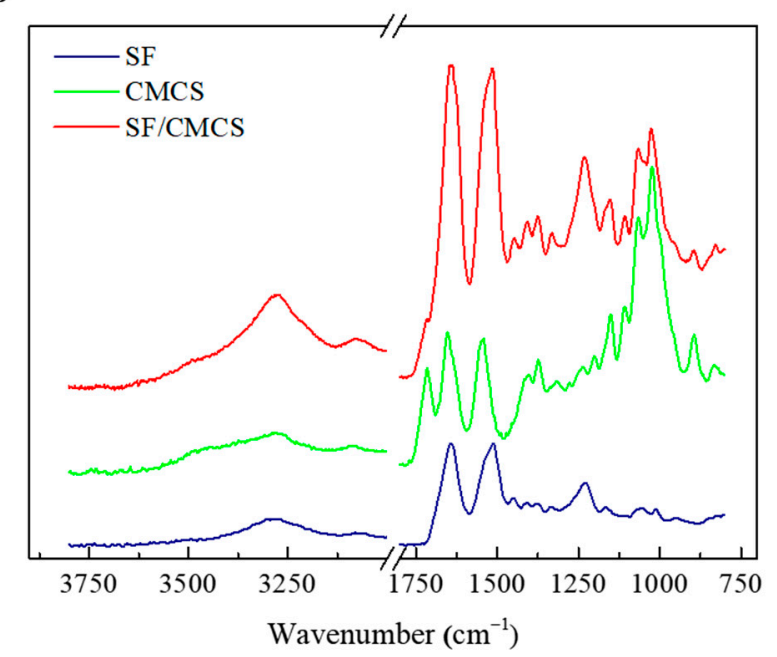

Figure 4. (a) Compression test results of the CMCS and SF/CMCS hydrogels and (b) FTIR spectra of the SF, CMCS, and $\mathrm{SF} / \mathrm{CMCS}$ hydrogels. Statistical analysis was performed using an unpaired, two-tailed $t$-test $(* * p<0.01, n=3)$.

An FTIR analysis of the CMCS and SF/CMCS hydrogels, as well as an SF sponge prepared through the lyophilization of SF aqueous solution, is shown in Figure $4 \mathrm{~b}$. The FTIR spectra of the SF/CMCS hydrogel exhibited the characteristic absorption bands of the SF sponge and the CMCS hydrogel with only an intensity difference, confirming that the SF/CMCS hydrogel is a combination of SF and CMCS.

\subsection{Thermogravimetric Analysis (TGA)}

The degradation and thermal stability behavior of lyophilized CMCS and SF/CMCS hydrogels, as well as an SF sponge prepared through lyophilization, were evaluated via TGA. The TGA curves (Figure 5a) revealed that weight loss occurred in two distinct stages. The first stage was due to the evaporation of absorbed moisture from $30^{\circ} \mathrm{C}$ to $150{ }^{\circ} \mathrm{C}$. The derivative thermogravimetric (DTG) curve of the SF/CMCS sample (Figure 5b) showed a peak water loss at $56{ }^{\circ} \mathrm{C}$ compared to $69^{\circ} \mathrm{C}$ and $91{ }^{\circ} \mathrm{C}$ for the CMCS and SF samples (Figure 5c,d), respectively. 
$\mathbf{a}$
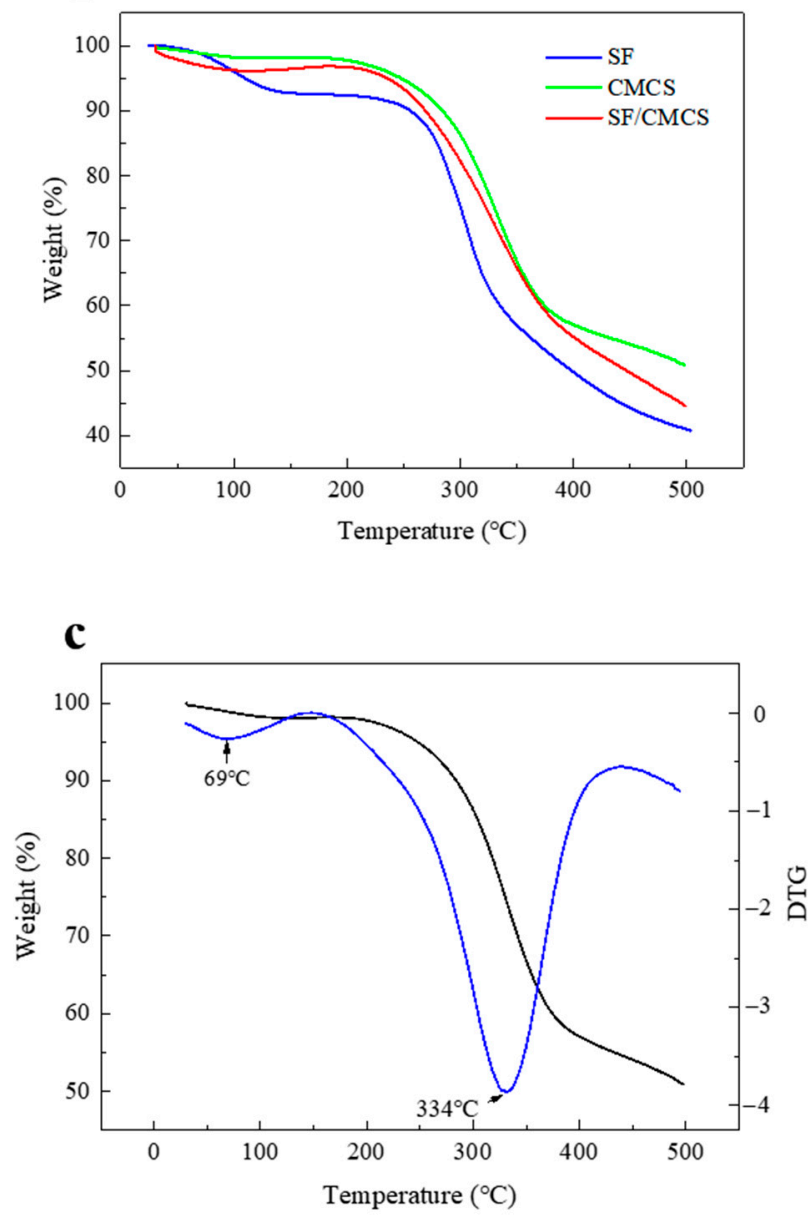

\section{b}
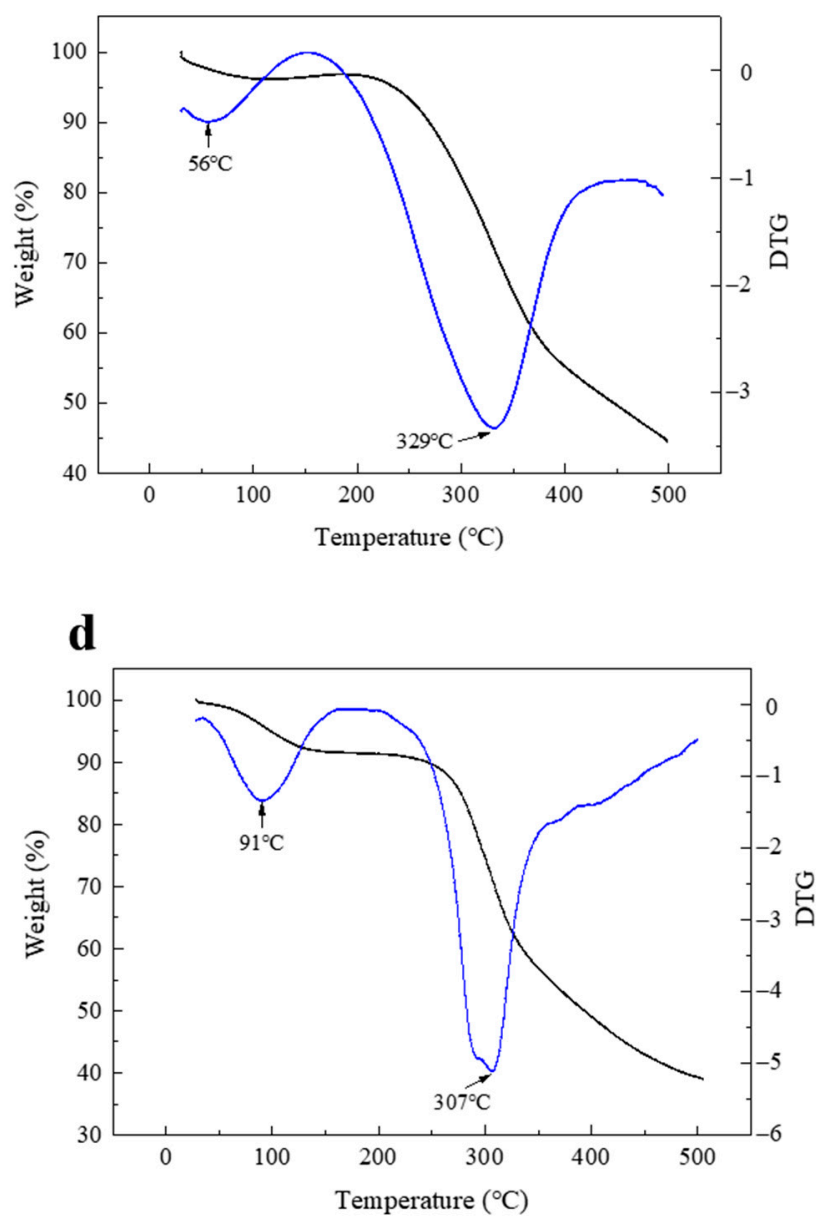

Figure 5. (a) TGA curves of the SF sponge, CMCS hydrogel, and SF/CMCS hydrogel. TGA traces (black dashed line) and the corresponding DTG thermographs (blue solid line) of (b) SF/CMCS hydrogel, (c) CMCS hydrogel, and (d) SF sponge.

The second stage related to the degradation of the samples from $150{ }^{\circ} \mathrm{C}$ to $500{ }^{\circ} \mathrm{C}$. The DTG peaks of the CMCS and SF samples showed a maximum value of $334^{\circ} \mathrm{C}$ and $307^{\circ} \mathrm{C}$, respectively, compared to $329^{\circ} \mathrm{C}$ for the SF/CMCS sample. These results are in accordance with previous findings that CMCS has better thermal stability than the regenerated silk fibroin $[25,26]$.

\subsection{Swelling Study and Water Vapor Transmission Rate (WVTR)}

The swelling capacity of the SF/CMCS hydrogel in response to different temperatures and $\mathrm{pH}$ values was assessed. Figure 6a shows the swelling kinetics of the SF/CMCS hydrogel in deionized water at $15{ }^{\circ} \mathrm{C}, 25^{\circ} \mathrm{C}, 37^{\circ} \mathrm{C}$, and $45^{\circ} \mathrm{C}$. Although the testing temperatures are different, SF/CMCS hydrogels reached swelling equilibrium within the first $12 \mathrm{~h}$ and demonstrated remarkable swelling behavior. As the temperature increased from $15^{\circ} \mathrm{C}$ to $45^{\circ} \mathrm{C}$, the equilibrium swelling ratio of the SF/CMCS hydrogel first increased then decreased. The equilibrium swelling ratio of the SF/CMCS hydrogel reached its maximum value at $37^{\circ} \mathrm{C}$ and reached its minimum value at $45^{\circ} \mathrm{C}$.

To investigate the influence of $\mathrm{pH}$ on the swelling behavior of the SF/CMCS hydrogel, solutions under four $\mathrm{pH}$ levels from 2.1 to 12.1 were prepared, and the ionic strength was maintained at $0.004 \mathrm{M}$ with $\mathrm{KCl}$ to eliminate the effect of ionic strength. Figure $6 \mathrm{~b}$ shows the swelling kinetics of SF/CMCS hydrogels in solutions with different $\mathrm{pH}$ values at room temperature $\left(25^{\circ} \mathrm{C}\right)$. The results show that $\mathrm{SF} / \mathrm{CMCS}$ hydrogels reached their swelling equilibrium within the first $12 \mathrm{~h}$. Furthermore, it was found that the degree of swelling reached a maximum at $\mathrm{pH} 7.4$ and decreased to a minimum at $\mathrm{pH} 12.1$. 
$\mathbf{a}$

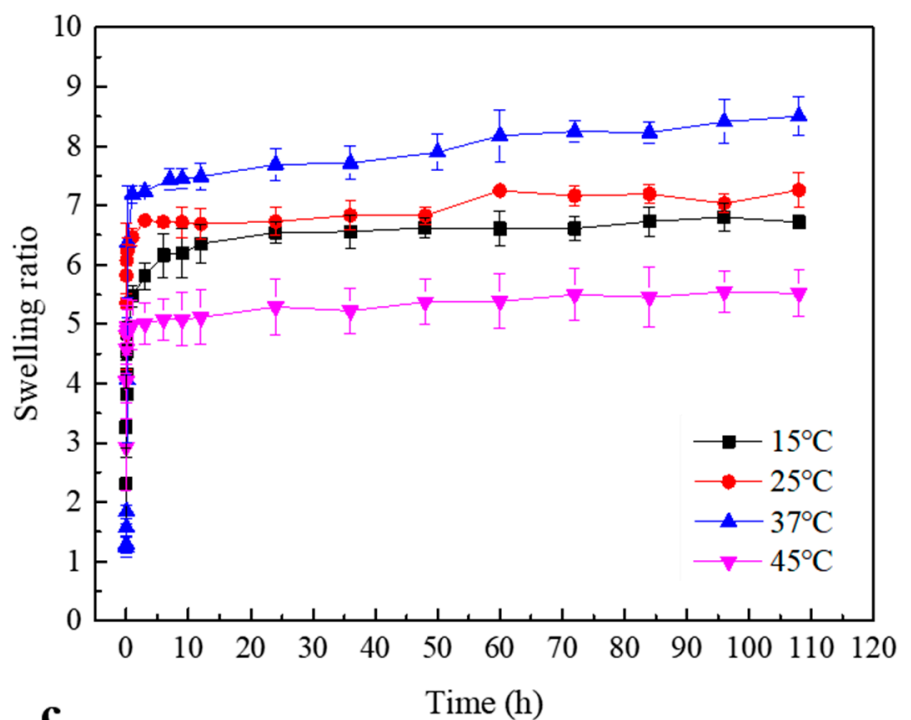

C

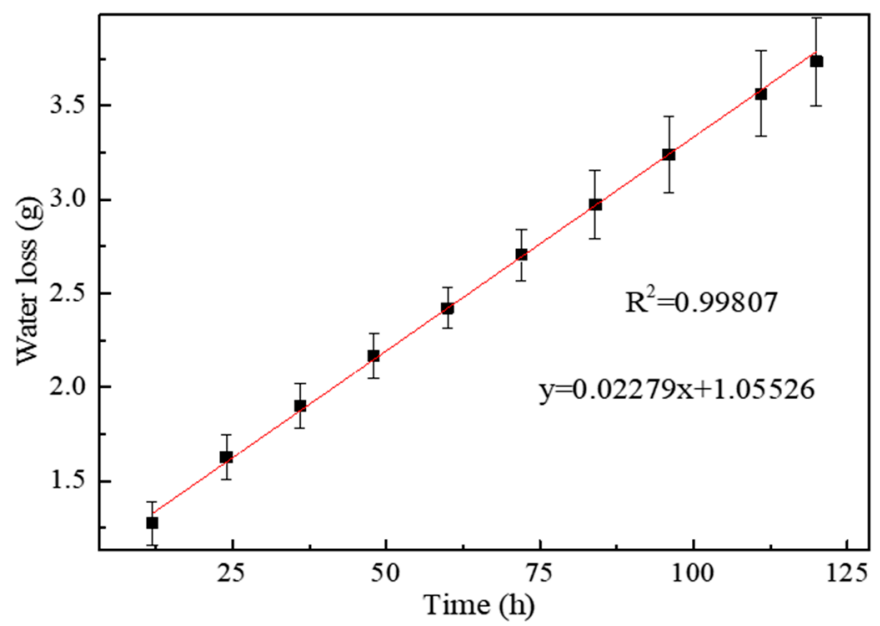

b
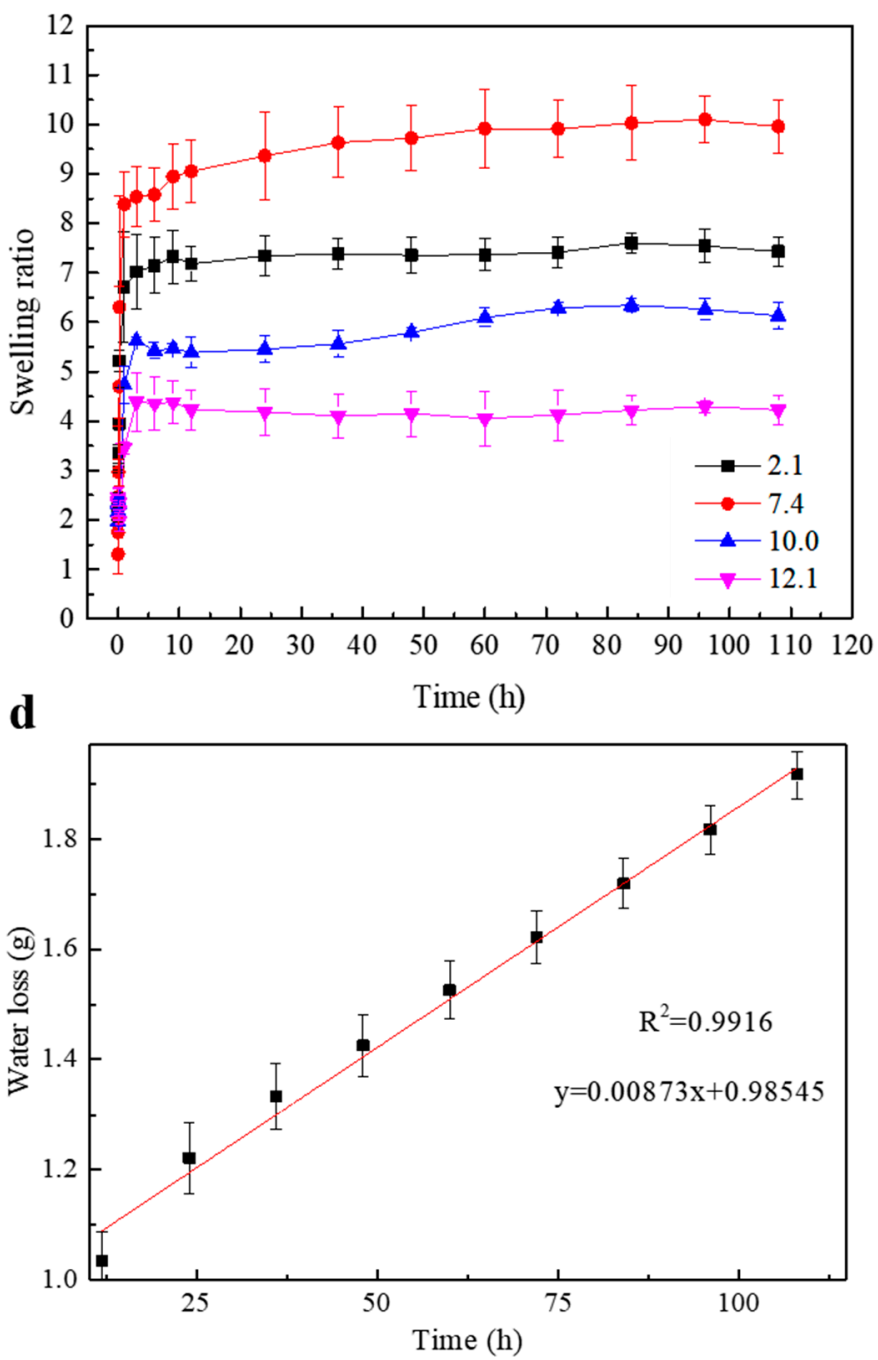

Figure 6. Swelling kinetics of SF/CMCS hydrogels at different temperatures (a) and pH values (b). Water vapor transmitted across the CMCS hydrogel (c) and SF/CMCS hydrogel (d).

As shown in Figure 6c, the water vapor permeability of the SF/CMCS hydrogel was $2095.2 \pm 68.2 \mathrm{~g} \cdot \mathrm{m}^{-2} \cdot \mathrm{day}^{-1}$, and the CMCS hydrogel demonstrated a WVTR of $5620.0 \pm 35.5 \mathrm{~g} \cdot \mathrm{m}^{-2}$ day $^{-1}$ (Figure 6d).

\subsection{In Vitro Stability Evaluation of the Hydrogels}

It is important to understand the physical stability of the hydrogel for wound dressing. The fast degradation would result in reduced hydration or diminished mechanical stiffness of the hydrogel. In contrast, slow degradation might result in sticking to the wound, which would need to be surgically removed [27-29]. The degradation kinetics of both SF/CMCS and CMCS hydrogels were studied and the results are shown in Figure 7. It is obvious that the mass of both hydrogels remain constant, and the hydrogel degraded slowly after 3 days. In addition, the degradation rate of the SF/CMCS hydrogel was smaller than that of the CMCS hydrogel with $44.72 \% \pm 4.48 \%$ and $37.74 \% \pm 3.69 \%$ of the remaining mass (RM\%), respectively. 


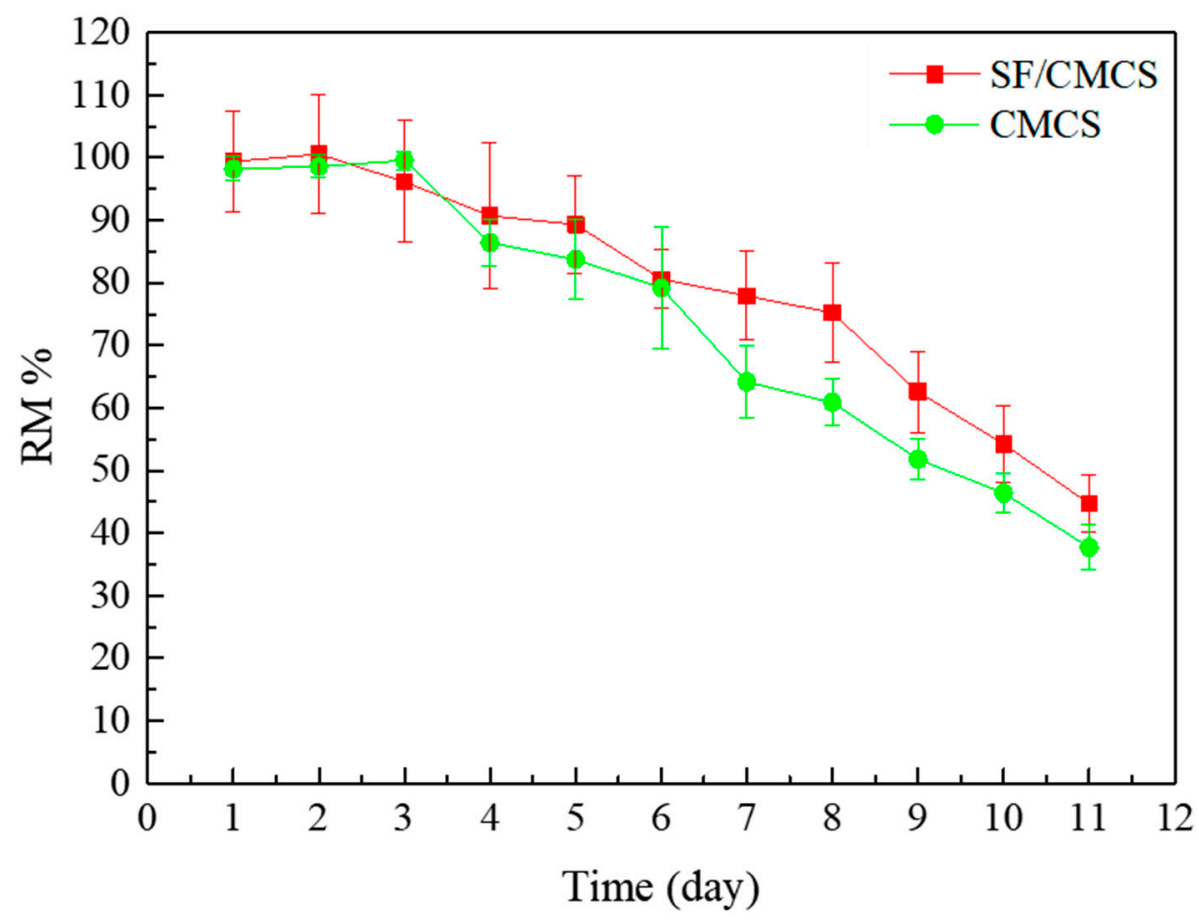

Figure 7. The degradation profiles of SF/CMCS and CMCS hydrogels.

\subsection{Antimicrobial Activity}

The results (Figure 8) demonstrated the good antibacterial activities of SF/CMCS and CMCS hydrogels against Escherichia coli (E. coli) and Staphylococcus aureus (S. aureus), respectively, determined by the colony counting method. The representative images of agar plates for the control group, the CMCS group, and the SF/CMCS group against E. coli and S. aureus are shown in Figure S6. The antibacterial property of the hydrogel was further confirmed in Section 5 of the Supplementary Materials, Figure S7.

\subsection{Cytotoxicity Test}

In this study, the cytotoxicity of the samples was assessed using the Cell Counting Kit-8 (CCK-8) assay. HEK-293 cells were chosen as the model cell because of their wide usage in toxicity evaluations for the safe use of materials [30-32]. The morphology of HEK-293 cells in the CCK-8 assay is shown in Figure S8. As depicted in Figure 9, cell proliferation after 3 days of culturing was assessed. The proliferation rate of the SF/CMCS hydrogel leaching liquor-treated group $(121.55 \% \pm 3.41 \%)$ was higher than that of the CMCS hydrogel leaching liquor-treated group $(103.54 \% \pm 2.99 \%)$. A similar conclusion can be drawn from the CCK-8 assay after 5 days of cell seeding: the SF/CMCS hydrogel $(153.24 \% \pm 9.98 \%$ cell proliferation rate) was more biocompatible than the CMCS hydrogel $(121.17 \% \pm 11.61 \%$ cell proliferation rate).

\subsection{In Vivo Wound Healing Assay}

To evaluate the wound healing effect of the prepared SF/CMCS hydrogel for the acceleration of wound repair, a full-thickness skin defect mouse model, created on the mouse dorsum with a biopsy punch, was investigated. Figure 10 displays the gross observations of wounds treated by sterile gauze (sterile gauze group), CMCS hydrogels, and SF/CMCS hydrogels at the 0th, 3rd, 7th, and 11th days. On day 3 , the wound region displayed decay and a dark red color. Broken skin was found on the edge of the wound (indicated by the white arrow in Figure 10d), which might have been caused by the shear force from the gauze and the mouse's skin moving. Treatment with the CMCS hydrogel slightly reduced the size of the wound region, whereas the SF/CMCS hydrogel significantly reduced the wound region, with the formation of granulation tissue. The 
percentage reduction in wound size of the sterile gauze, the CMCS hydrogel, and the CMCS/SF hydrogel treatment groups on day 3 were calculated using ImageJ software (Table S2) to be $6.29 \% \pm 0.98 \%, 14.20 \% \pm 6.05 \%$, and $47.09 \% \pm 4.09 \%$, respectively. On the 7 th day after surgery, the wound margin of all groups receded toward the wound center, in which the CMCS/SF group exhibited a better rate of wound healing, with a percentage reduction in wound size of $83.03 \% \pm 0.66 \%$, compared with the sterile gauze group and the CMCS group. After 11 days of treatment, the SF/CMCS group displayed almost complete wound contraction, as shown in Figure 101.

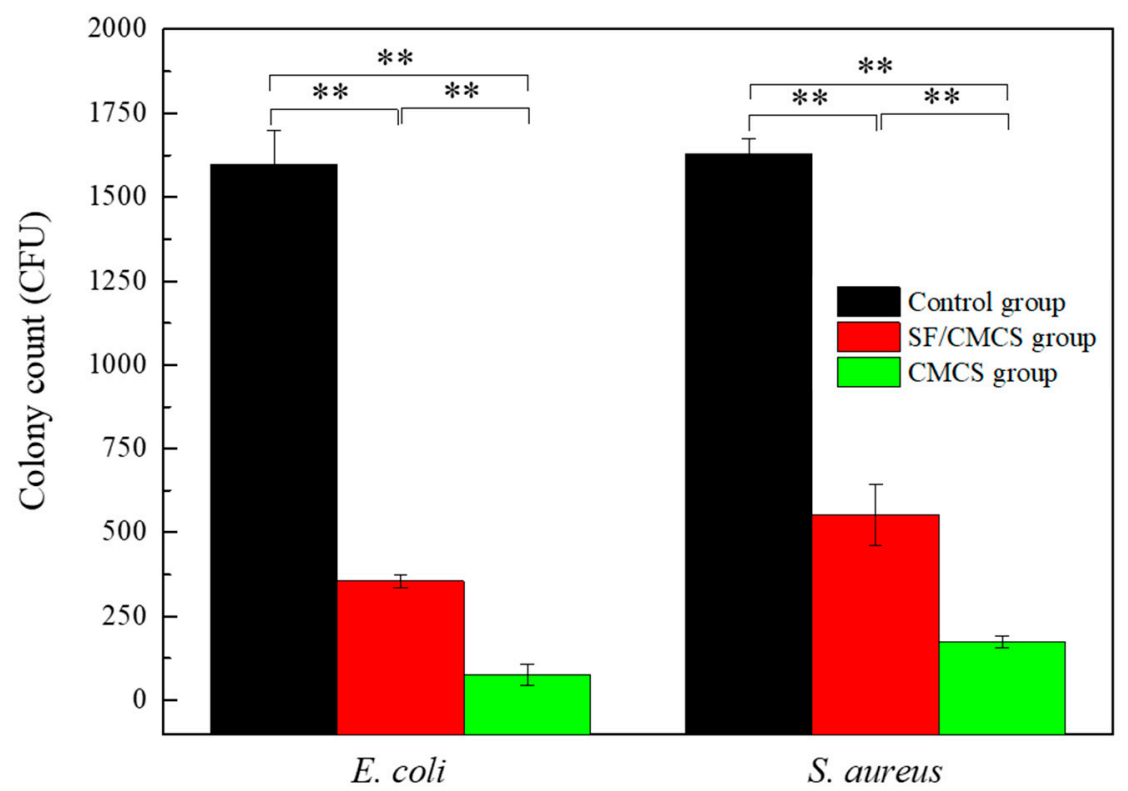

Figure 8. Comparison of the colony numbers of S. aureus and E. coli on different agar plates. Statistical analysis was performed using an unpaired, two-tailed $t$-test $(* * p<0.01, n=3)$.

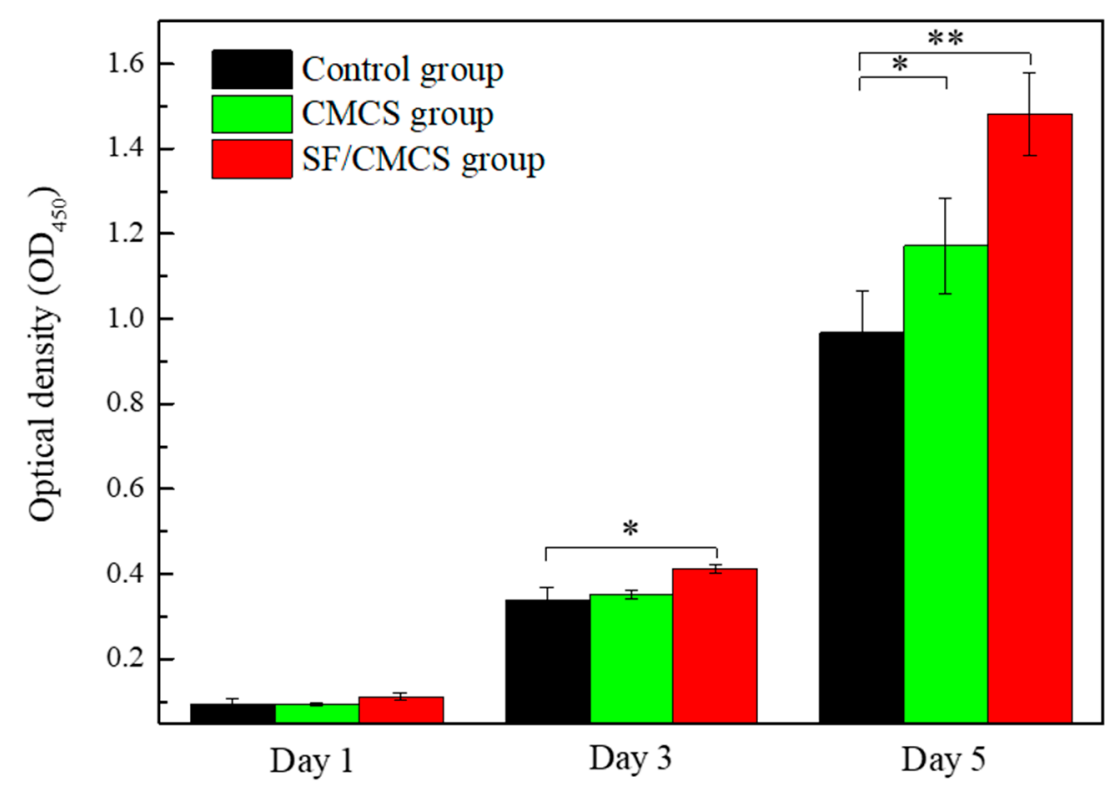

Figure 9. Viability of HEK-293 cells after 1 day, 3 days, and 5 days of contact with leaching liquor obtained from CMCS hydrogel and SF/CMCS hydrogel. Statistical analysis was performed using an unpaired, two-tailed $t$-test $\left.{ }^{*} p<0.05,{ }^{* *} p<0.01, n=3\right)$. 

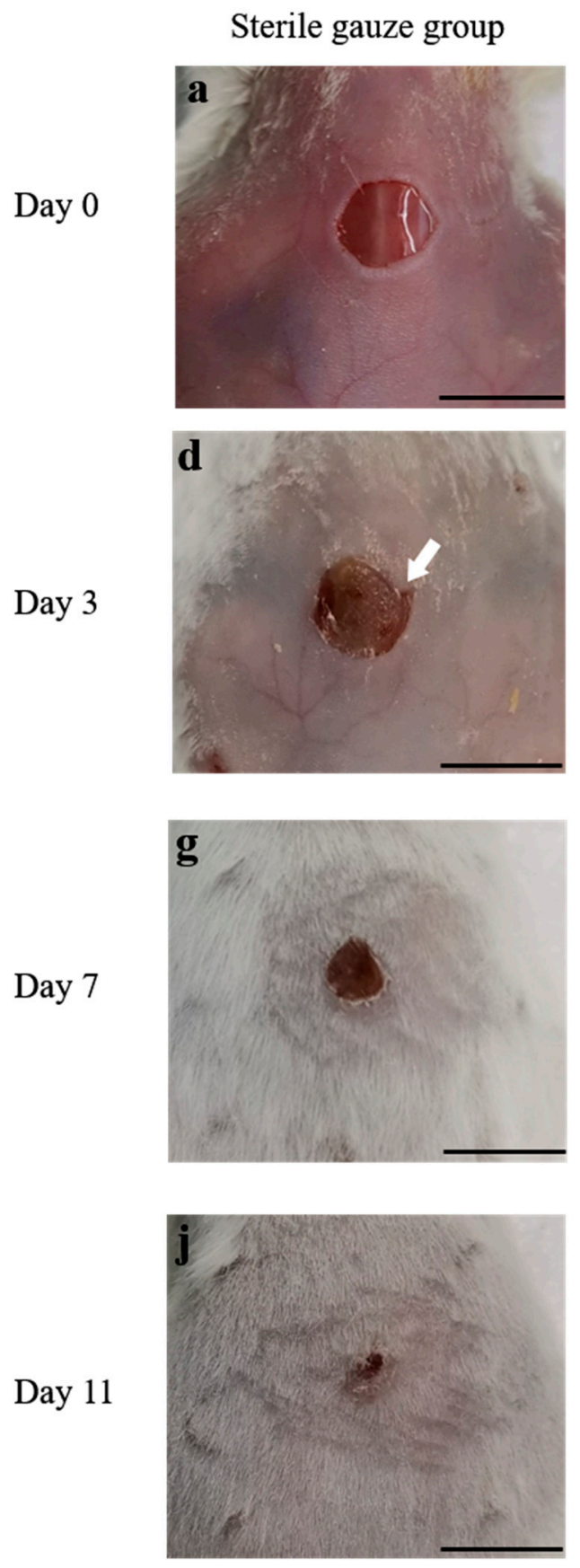
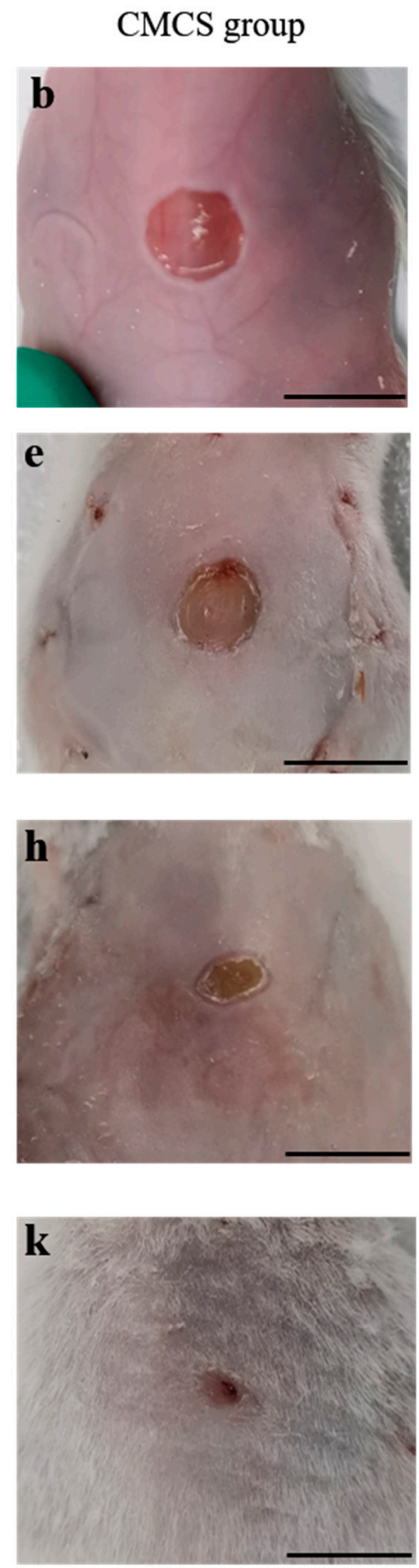

$\mathrm{SF} / \mathrm{CMCS}$ group
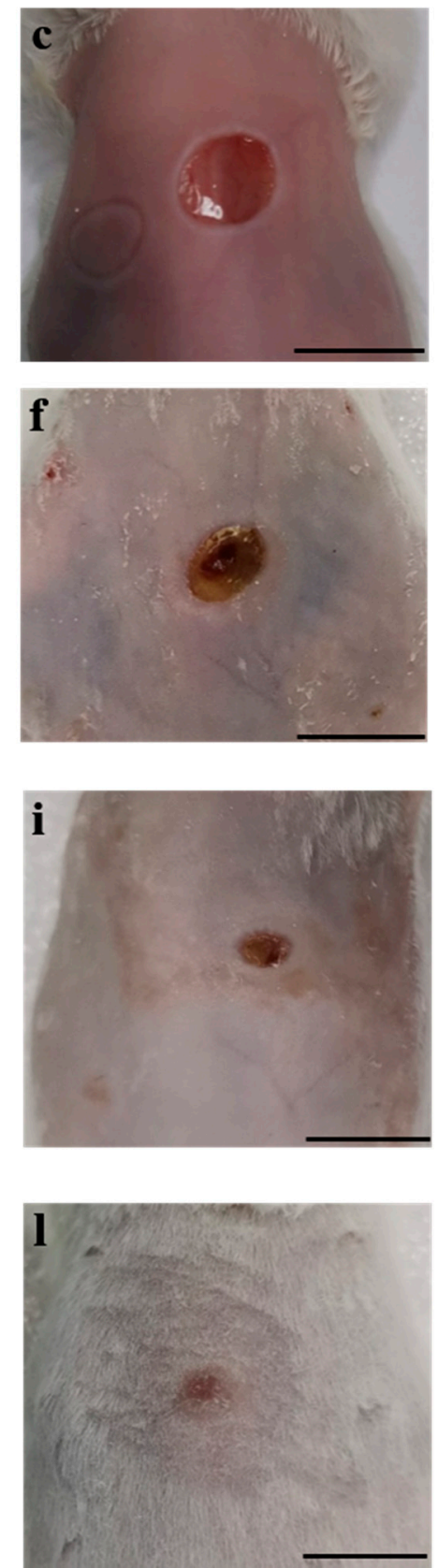

Figure 10. Wound healing of the sterile gauze group, CMCS group, and SF/CMCS group. (a,d,g,j) are the gross observations of wounds treated by sterile gauze at the 0 th, $3 \mathrm{rd}, 7$ th, and 11 th days, respectively. $(\mathbf{b}, \mathbf{e}, \mathbf{h}, \mathbf{k})$ are the gross observations of wounds treated by CMCS hydrogels at the 0 th, 3rd, 7 th, and 11th days, respectively. $(\mathbf{c}, \mathbf{f}, \mathbf{i}, \mathbf{l})$ are the gross observations of wounds treated by SF/CMCS hydrogels at the 0 th, 3rd, 7th, and 11th days, respectively (scale bar: $1 \mathrm{~cm}$ ).

On the basis of hematoxylin and eosin (H\&E) stained slides, the length of the newly formed epithelium was measured using ImageJ software (ImageJ 1.6.0) and is indicated by green arrows in Figure 11a. As shown in Figure 11a,b, on the third day after surgery, the length of the newly formed epithelium in the SF/CMCS group $(466.61 \pm 23.99 \mu \mathrm{m})$ was longer than those in the CMCS group $(342.56 \pm 18.86 \mu \mathrm{m})$ and the sterile gauze group $(201.27 \pm 40.58 \mu \mathrm{m})$. The groups showed a similar tendency on the 7th day, with a length of $953.73 \pm 36.76 \mu \mathrm{m}$ for the SF/CMCS group, $795.22 \pm 17.80 \mu \mathrm{m}$ for the CMCS group, and $793.16 \pm 16.27 \mu \mathrm{m}$ for the sterile gauze group. 
a

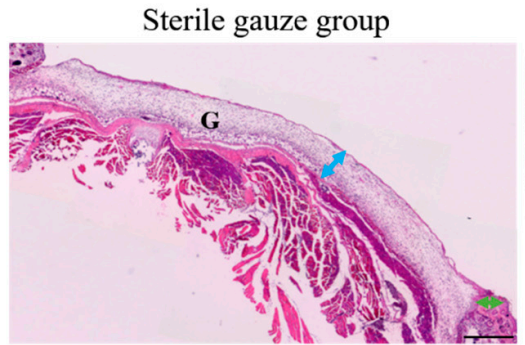

Day 3

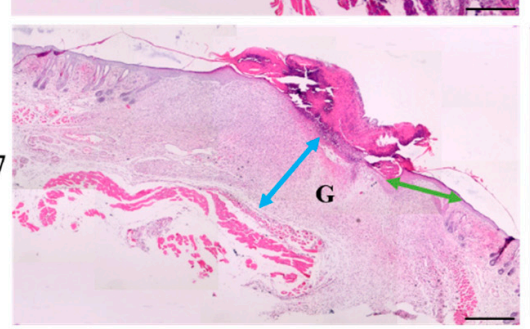

Day 7

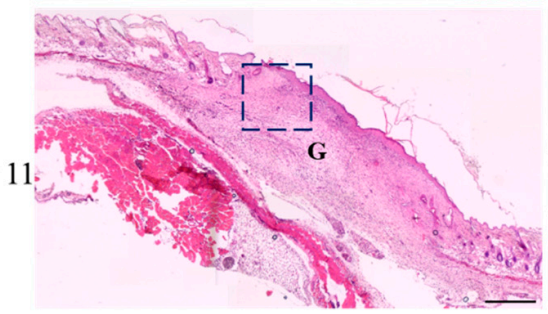

\section{b}

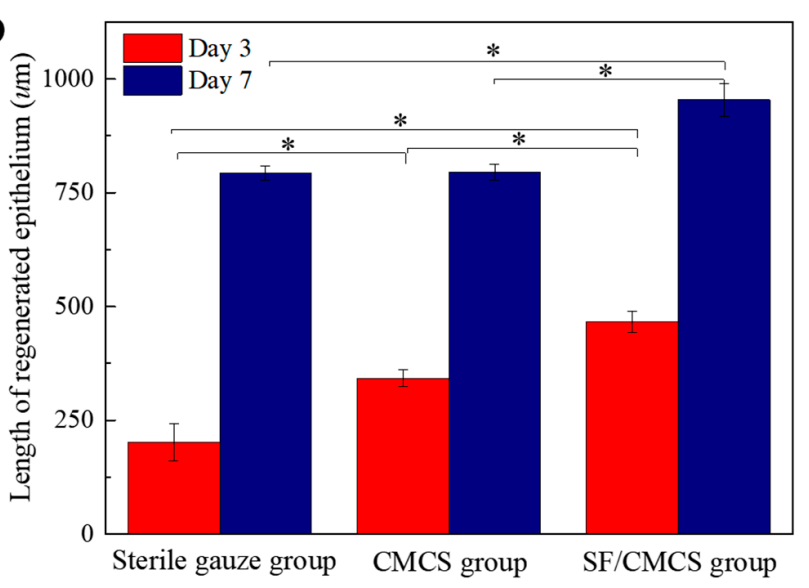

CMCS group
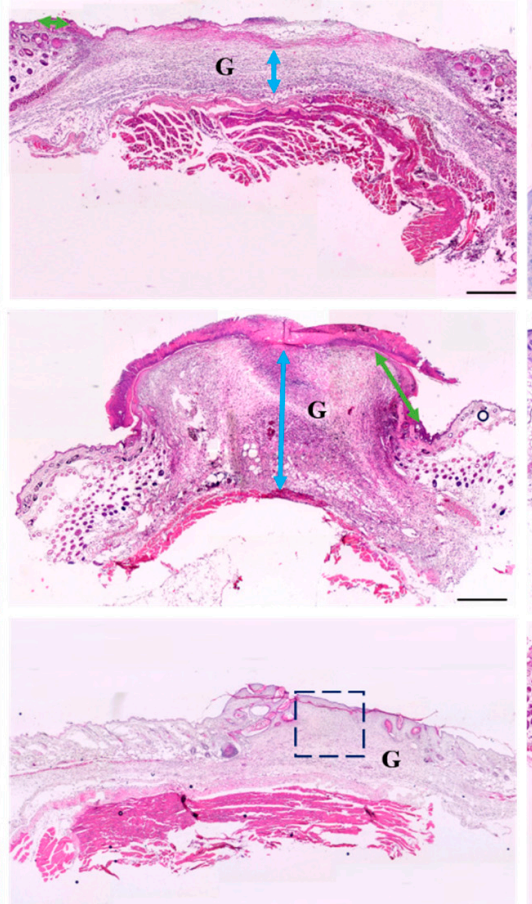

SF/CMCS group
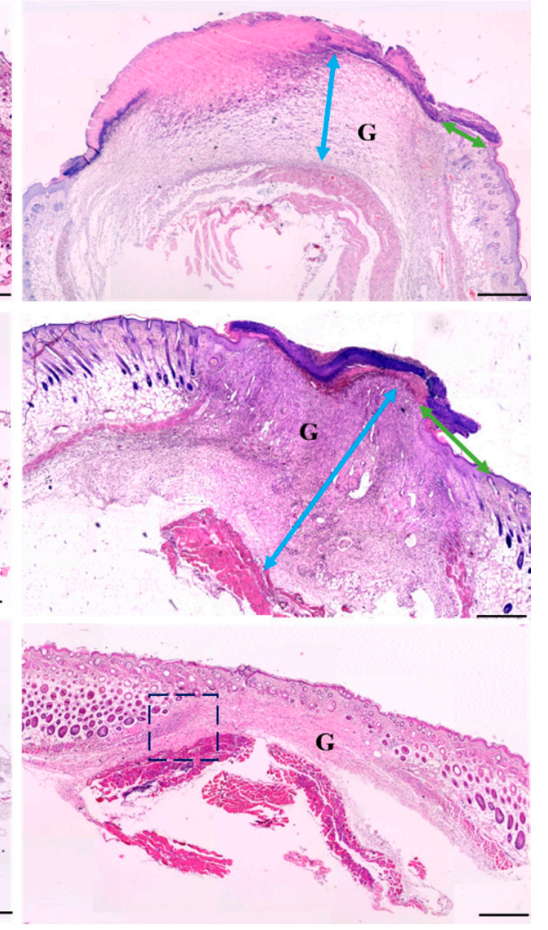

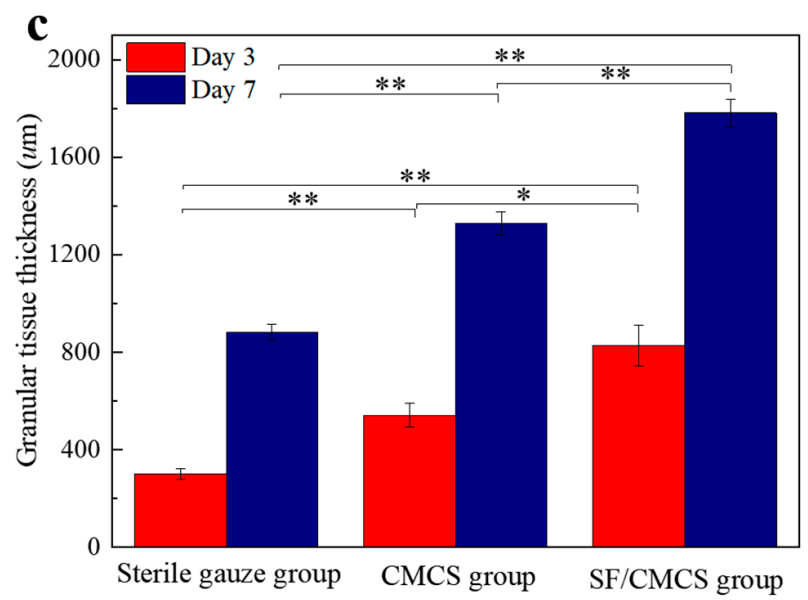

d

Sterile gauze group
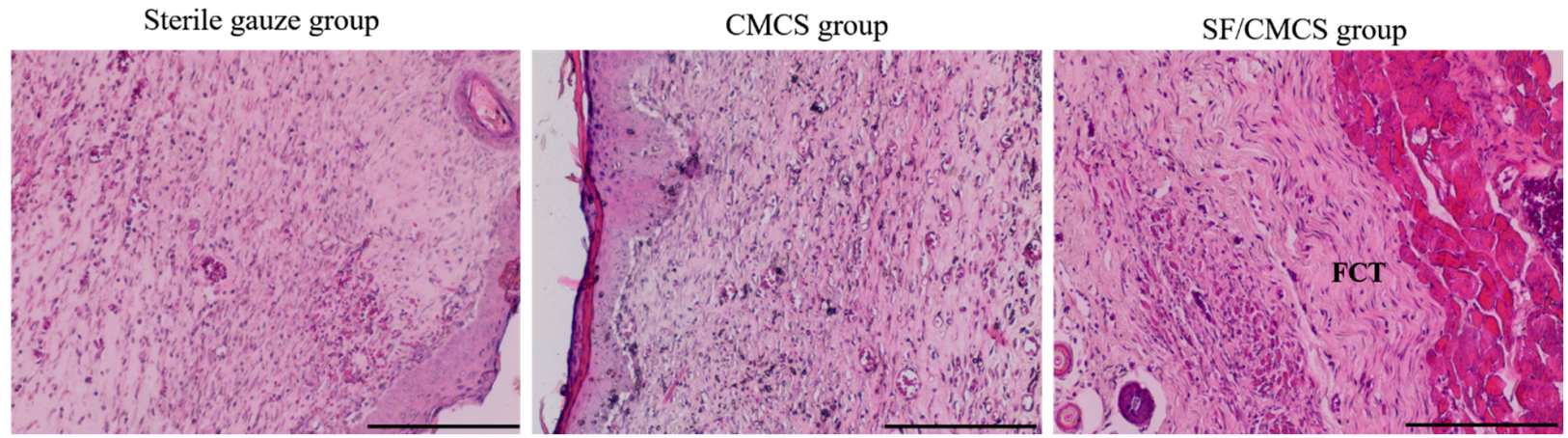

Figure 11. (a) Analysis of H\&E staining in the sterile gauze group, CMCS group, and SF/CMCS group at 3, 7, and 11 days, respectively. The blue arrow represents the thickness of granulation tissue, and the green arrow represents the length of regenerated epithelium (G: granulation tissue, scale bar: $500 \mu \mathrm{m}$ ). The regenerated epithelium length (b) and average granulation tissue thickness (c) of the three groups were compared on the 3rd and 7th days. Statistical analysis was performed using an unpaired, two-tailed $t$-test $\left({ }^{*} p<0.05,{ }^{* *} p<0.01, n=3\right)$. (d) The granulation tissue of the three groups was observed at 11 days, corresponding to the boxed regions in (a) (FCT: fibrous connective tissue, scale bar: $200 \mu \mathrm{m}$ ). 
The thickness of the granulation tissue of all samples was measured using IPP software (Image-Pro Plus 6.0, Media Cybernetics, Rockville, MD, USA) and is marked by the blue arrows in Figure 11a. On day 3 and day 7, the SF/CMCS group showed significantly thicker granulation tissue than both the CMCS group and the control group, of which the control group had the lowest granulation accumulation.

On the 11th postoperative day, the wounds of all groups were epithelialized. The H\&E section of the SF/CMCS group, as depicted in Figure 11d, shows fibrous connective tissue (FCT) with regularity, but no fibrous connective tissue was observed in the H\&E section of the sterile gauze and CMCS groups.

\section{Discussion}

The thickness of the CMCS and SF/CMCS hydrogels gradually increased with electrodeposition time (Figure $1 \mathrm{a}-\mathrm{p}$ ), which is consistent with the observations of other studies on hydrogel preparation via electrodeposition $[10,18,19]$. It can be observed that the thickness of SF/CMCS hydrogels is greater than that of CMCS hydrogels prepared under identical conditions. These results indicate that cross-linking interactions occurred in the SF/CMCS solution.

The SEM observations (Figure 1q-t) found that the SF/CMCS hydrogel had a crosslinked structure with a hierarchical porous architecture, which is obviously different from the layered structure of the CMCS hydrogel. This result might be due to the prevention of sheet-structure formation by means of the interaction between SF and CMCS. It has been reported that hydrogels with a porous structure help to transport oxygen to the wound, absorb wound exudate, and balance the moisture level at the wound site [33,34]. Hence, compared to CMCS hydrogels, SF/CMCS hydrogels exhibit superior characteristic features in terms of the physical structures of wound dressings. In addition, the higher crosslinking network of the SF/CMCS hydrogel might be the reason for its higher stability compare to that of the CMCS hydrogel.

The viscosity of a mixture of two fluids can be determined according to the Arrhenius equation [35] as follows:

$$
\ln \eta_{m}=\phi_{1} \ln \eta_{1}+\phi_{2} \ln \eta_{2}
$$

where $\eta_{m}$ is the viscosity of fluid mixture, $\phi_{i}$ is the volume fraction of component $i$, and $\eta_{i}$ is the viscosity of component $i$.

The theoretical viscosity of the prepared SF/CMCS mixture can be calculated as $19.96 \mathrm{mpa} \cdot \mathrm{s}$, which is smaller than the experimental data, indicating that some interaction has occurred between SF and CMCS. Because the carboxyl groups (pKa = 4.5) [36] of CMCS and SF $(\mathrm{pI}=4.5)$ [37] are predominantly negatively charged at the $\mathrm{pH}$ of the mixture $(\mathrm{pH}=8.76)$, the formation of an electrostatic interaction between SF and CMCS is less favorable. We believe this difference in the calculated theoretical and experimental viscosities of the SF/CMCS mixture was mainly due to the formation of hydrogen bonds between SF and CMCS, as the rheological behavior of an aqueous polymer mainly depends on the relative strength of the hydrogen bonding within the solution, and more strong hydrogen bonds would greatly increase the viscosity [38,39].

The compression test results (Figure 4) reveal that the SF/CMCS hydrogel possessed enhanced compressive mechanical properties compared with the CMCS hydrogel, which can be attributed to the interaction between SF and CMCS molecules. As mechanical properties can reflect structural stability [10], the results demonstrate that the electrodeposition of the SF/CMCS mixture has a better gel-forming effect.

The TGA curves shown in Figure 5 indicate that water was loosely held by the SF/CMCS sample and easily removed at a lower temperature, compared to the water physically entrapped by SF and CMCS. This is because most hydrophilic groups from SF and CMCS are already involved in hydrogen bonding, therefore exhibiting a lower moisture absorption level [40]. As shown in Figure 5a, a slow, continuous mass loss was observed in the TGA curve of the SF/CMCS sample without matching the TGA curves of SF and CMCS. This result suggests a considerable interaction between SF and CMCS [41]. The SF/CMCS 
sample exhibited lower thermal stability than the CMCS sample, possibly because the introduction of RSF decreased the crystallinity of CMCS. This trend in the thermal stability of the samples is supported by the mass of the remaining samples (Figure 5a).

Swelling is an important feature of hydrogel dressings. Large water absorption capacities allow hydrogel dressings to absorb wound fluids and exudates [42]. The equilibrium swelling ratio of the SF/CMCS hydrogel first increased and then decreased with temperature (Figure 6a). This trend can be explained in terms of H-bonding within the hydrogel, which was weakened by the larger thermal motion at higher temperatures. This $\mathrm{H}$-bond weakening loosens the hydrogen bond cross-links, enlarging the equilibrium swelling ratio. As the temperature was further increased to $45^{\circ} \mathrm{C}$, the equilibrium swelling ratio of the $\mathrm{SF} / \mathrm{CMCS}$ hydrogel decreased dramatically, caused by hydrogel dissociation due to the breaking of hydrogen bonds.

The surface $\mathrm{pH}$ of a wound varies [43]. The influence of $\mathrm{pH}$ on the swelling behavior of the SF/CMCS hydrogel was evaluated. The swelling equilibrium state of SF/CMCS hydrogels in solution is $\mathrm{pH}$-dependent, which can be largely attributed to the ionization/deionization processes of $\mathrm{pH}$-sensitive functional groups. In an acidic environment $(\mathrm{pH} 2.1)$, carboxylic groups $\left(-\mathrm{COO}^{-}\right)$introduced by carboxymethyl chitosan were protonated as $-\mathrm{COOH}$, resulting in a stronger hydrogen-bonding interaction. Consequently, the hydrogel network shrank and the swelling equilibrium decreased. When the $\mathrm{pH}$ values increased to seven, the carboxyl group was ionized, and the electrostatic repulsion between molecular chains became dominant, leading to an expansion of the hydrogel network [44]. However, when the $\mathrm{pH}$ values continued to increase to 10.0 and $12.1, \mathrm{Na}^{+}$and $\mathrm{K}^{+}$in the solution combined with the $-\mathrm{COO}^{-}$groups of the SF/CMCS hydrogel $\left(\mathrm{Na}^{+}\right.$and $\mathrm{K}^{+}$were introduced when preparing the buffer solutions with $\mathrm{pH}$ values of 10.0 and 12.1; see Section 3 of the Supplementary Materials). This charge shielding neutralized the electrostatic interactions and reduced the electrostatic repulsion. The gel network therefore shrank into a compact structure with a decreased swelling equilibrium $[45,46]$. The above experiments prove that the prepared SF/CMCS hydrogels are $\mathrm{pH}$ - and temperature-sensitive, with the capability to absorb exudate in the wound environment.

An ideal wound dressing can control water vapor loss from a wound at an optimal range (2000-2500 $\mathrm{g} \cdot \mathrm{m}^{-2} \cdot$ day $^{-1}$ ) to avoid either excessive dehydration or exudate accumulation at the wound region [47]. Based on the obtained WVTR data, it was found that the SF/CMCS hydrogel, with a WVTR of $2095.2 \pm 68.2 \mathrm{~g} \cdot \mathrm{m}^{-2} \cdot \mathrm{day}^{-1}$, could maintain a suitable moisture environment for wound healing; whereas the CMCS hydrogel, with a WVTR of $5620.0 \pm 35.5 \mathrm{~g} \cdot \mathrm{m}^{-2}$. day ${ }^{-1}$, may result in dehydration or slow healing of the wound area. The hydrogen bonding between SF and CMCS presumably weakens their hydrophilicity, consequently reducing the water vapor transmission rate of the SF/CMCS hydrogel [48]. Compared to the CMCS hydrogel, the SF/CMCS hydrogel is a more suitable wound dressing that can create environments that are supportive of earlier healing outcomes.

Wound infections caused by bacteria could cause either a delay in wound healing or deterioration of the wound [49-51]. Therefore, an ideal wound dressing should have broad-spectrum antibacterial activity [34]. SF/CMCS hydrogels exhibit better antibacterial activity than the control group. Their rates of bacteriostasis against $E$. coli and S. aureus were $77.73 \% \pm 1.24 \%$ and $66.08 \% \pm 5.54 \%$, respectively. CMCS hydrogels exhibited much better bacteriostasis rates against E. coli $(95.21 \% \pm 1.94 \%)$ and S. aureus $(89.37 \% \pm 1.03 \%)$ than the SF/CMCS group. Although CMCS possesses excellent antibacterial properties [52], silk fibroin has little or no inherent antibacterial properties [53,54], Compared to the CMCS hydrogel, the presence of silk fibroin lowers the content of CMCS within the SF/CMCS hydrogel under the same mass weight, resulting in a weaker antibacterial performance.

In addition to antibacterial properties, biocompatibility is another inherent property that should be evaluated to determine whether SF/CMCS hydrogels are qualified to serve as wound dressings. Results of the CCK-8 assay (Figure 9) suggested that the prepared SF/CMCS hydrogels were biocompatible and showed greater cell proliferation than CMCS hydrogels, although CMCS hydrogels can also promote cell proliferation. This property is 
due to the presence of the Arg-Gly-Asp sequence in the silk fibroin, which is effective in promoting cell proliferation [55,56].

Gross wound observations (Figure 10) showed that the prepared SF/CMCS hydrogel can induce wound contraction and accelerate wound closure.

The four phases of wound healing include hemostasis, inflammation, proliferation, and maturation [33], and can be determined by the length of newly formed epithelium and the thickness of the granulation tissue [57,58]. The length of newly formed epithelium can be defined as the distance between the tip of the migrating keratinocytes and the first hair follicle observed on the side of the wound margin [59,60]. Wound re-epithelialization can prevent infection and excessive moisture loss [61]. These results, relating to the regenerative epithelium length, indicate that the SF/CMCS hydrogel was able to promote wound healing via wound re-epithelialization, as compared with the CMCS group and the sterile gauze group.

Histologically, granulation tissue appears bright red and granular. It is a collection of small, microscopic blood vessels and is characterized by the proliferation of fibroblasts, accompanied by inflammatory cell infiltration [62]. Granulation tissue plays an important role in the process of wound healing and fill wounds, conferring protection from infection and further damage [63]. On days 3 and 7, the granulation tissue thickness in the SF/CMCS group was substantially greater than those of the other groups (Figure 11c), and there was obviously greater granulation tissue formation in the CMCS group than in the sterile gauze group. Therefore, SF/CMCS and CMCS hydrogels appear to accelerate wound healing during the granulation phase, but SF/CMCS hydrogels exhibited superior wound healing compared to that of CMCS hydrogels.

As the granulation tissue began to mature, the wound area was filled with aligned fibrous connective tissue, which contributes to the formation of new tissue and subsequent tissue remodeling $[64,65]$. This transformation could be seen on the 11th day of wound healing in mice treated with the SF/CMCS hydrogel, whereas it was not observed in the CMCS group or in the sterile gauze group, indicating that the SF/CMCS hydrogel could facilitate the formation of fibrous connective tissue for wound repair.

The above results indicate that SF/CMCS hydrogels could promote wound healing by favoring granulation tissue formation, wound re-epithelialization, and the conversion of granulation tissue into fibrous connective tissue. The promising wound healing properties of the SF/CMCS hydrogel are consistent with other experimental results showing that $\mathrm{SF} / \mathrm{CMCS}$ hydrogels can provide a good barrier to prevent dehydration of the wound site and accelerate cell proliferation. The wound healing-promoting characteristics of the SF/CMCS hydrogel can also be attributed to the presence of the inherent tripeptide sequence of arginine-glycine-aspartic acid (RGD) in the protein fibroin sequences, which can promote cell adhesion and migration [66]. To the best of our knowledge, this is the first time that the therapeutic effect of an SF/CMCS composite has been evaluated in wound healing.

\section{Materials and Methods}

\subsection{Materials and Reagents}

Cocoons of silkworm Bombyx mori (a Chinese strain demoted as 872) were provided by College of Biotechnology, Southwest University, China. Carboxymethyl chitosan (CMCS, pale yellow powder, viscosity $\leq 50 \mathrm{mpa} \cdot \mathrm{s}$, and degree of substitution $\geq 95.0 \%$ ) was purchased from Shanghai Ryon Biological Technology CO., Ltd. (Shanghai, China). Sodium carbonate, sodium chloride, aminoacetic acid, potassium chloride, boric acid, xylene, potassium dihydrogen phosphate, and disodium hydrogen phosphate dodecahydrate were purchased from KeLong Chemical Reagent Co., Ltd. (Chengdu, China). Calcium chloride was purchased from Yuanye Bio-Technology Co., Ltd. (Shanghai, China). Anhydrous ethanol and hydrochlorc acid (36.0-38.0\%) were purchased from Chuandong Chemical Co., Ltd. (Chongqing, China). Potassium bromide was purchased from Sangon Biotech Co., Ltd. (Shanghai, China). Bradford protein assay kit was purchased from Beyotime Biotechnology 
Co., Ltd. (Shanghai, China). Sodium hydroxide was purchased from Jinshan Chemical Test Co., Ltd. (Chengdu, China). Tryptone was purchased from Beijing Aoboxing Bio-tech Co., Ltd. (Beijing, China). Yeast extract was purchased from Oxoid Co., Ltd. (Basingstoke, Britain). Trichloroacetaldehyde hydrate and formaldehyde solution were purchased from Shanghai Aladdin Bio-Chem Technology Co., Ltd. (Shanghai, China). A Cell Counting Kit8 (CCK-8) was purchased from Mei5 Biotechnology Co., Ltd. (Beijing, China). Hematoxylin and eosin stain solution was purchased from Nanchang Yulu Experimental Equipment Co., Ltd. (Nanchang, China). All chemicals were of analytical grade and were used without further purification. Deionized water was obtained from a Milli-Q Direct-8 purification system (resistivity $>18 \mathrm{M} \Omega \mathrm{cm}$, Millipore Inc., Boston, MA, USA) onsite and was used in all experiments.

\subsection{Fabrication of SF/CMCS Hydrogel}

\subsubsection{Preparation of RSF Solution}

Cocoons from Bombyx mori were cut into pieces, boiled for $30 \mathrm{~min}$ in an aqueous solution of $0.5 \% \mathrm{Na}_{2} \mathrm{CO}_{3}$, and rinsed with water to extract sericin. This operation was repeated twice. Then, the degummed silk fiber was dissolved in a ternary solvent of $\mathrm{CaCl}_{2}: \mathrm{CH}_{3} \mathrm{CH}_{2} \mathrm{OH}: \mathrm{H}_{2} \mathrm{O}$, in a molar ratio of $1: 2: 8$, at $70{ }^{\circ} \mathrm{C}$ until the silk fibroin was completely dissolved. Once the silk fibroin salt solution was cooled to room temperature, it was dialyzed (MWCO 8000, Solarbio, Beijing, China) against deionized water for 3 days, changing the water every $2 \mathrm{~h}$. After dialysis, the silk fibroin solution was filtered through gauze and centrifuged at $4{ }^{\circ} \mathrm{C}$ and $8000 \mathrm{rpm}$ to remove silk aggregates and debris. The resulting RSF solution obtained was concentrated at $60^{\circ} \mathrm{C}$ in a water bath to prepare silk fibroin solutions with different mass fractions.

\subsubsection{Preparation of CMCS Solution}

The CMCS solution was prepared by dissolving CMCS in deionized water, and the $\mathrm{pH}$ was adjusted with $5 \mathrm{M}$ sodium hydroxide to 12 for complete dissolution [67]. Our experiments suggest that $4 \%$ is the highest mass/volume ratio for maintaining CMCS aqueous solution in a stable state without precipitation.

\subsubsection{Preparation of SF/CMCS Hydrogel}

SF solution of a certain mass fraction was blended with $4 \%$ CMCS solution for $4 \mathrm{~h}$ at $250 \mathrm{rpm}$ at room temperature $\left(25^{\circ} \mathrm{C}\right)$ to prepare the desired SF/CMCS mixture. It has been reported that low temperature benefits hydrogen bond formation [68]. Therefore, to facilitate the formation of intermolecular hydrogen bonds between SF and CMCS, the $\mathrm{SF} / \mathrm{CMCS}$ mixture was kept in a refrigerator at $4{ }^{\circ} \mathrm{C}$ overnight.

An electrochemical workstation (CHI760E, Shanghai Chenhua Instruments Limited, China) and a three-electrode assembly were used for the SF/CMCS hydrogel fabrication using a graphite anode, an $\mathrm{Ag} / \mathrm{AgCl}$ reference electrode, and a platinum cathode. The electrodes were immersed in SF/CMCS aqueous solution, which contained $0.25 \%(w / v)$ $\mathrm{NaCl}$ as electrolyte, and a voltage in direct current (DC) mode was applied over a period of time by means of chronoamperometry. The generated hydrogel was gently peeled from the graphite electrode and then carefully rinsed with deionized water to remove residue.

\subsection{Evaluation of SF Content in SF/CMCS Hydrogel}

The percentage of SF $(n \%)$ within the prepared SF/CMCS hydrogel was measured based on the Bradford protein assay [69] using the following equation:

$$
n \%=\frac{C_{1} V_{1}-C_{2} V_{2}}{m} \times 100 \%
$$

where $C_{1}$ is the concentration of SF in the SF/CMCS mixture before gelation, and $C_{2}$ is the concentration of $\mathrm{SF}$ in the remaining solution after gelation. $C_{1}$ and $C_{2}$ can be determined from the standard calibration curves presented in Figure S9a and S9b, respectively. $m$ is 
the mass of the prepared SF/CMCS hydrogel after lyophilization. $V_{1}$ is the volume of the $\mathrm{SF} / \mathrm{CMCS}$ mixture before gelation and is $20 \mathrm{~mL}$; and $V_{2}$ is the volume of the remaining solution after gelation. Therefore, $C_{1} V_{1}$ is the content of SF in the $20 \mathrm{~mL}$ of SF/CMCS mixture, $C_{2} V_{2}$ is the content of SF in the remaining solution after the SF/CMCS hydrogel is prepared, and $C_{1} V_{1}-C_{2} V_{2}$ represents the mass of $\mathrm{SF}$ in the SF/CMCS hydrogel.

\subsection{Quantifying the SF Release}

The prepared SF/CMCS hydrogel was placed in a weighing bottle containing $20 \mathrm{~mL}$ $(V)$ of deionized water at $25{ }^{\circ} \mathrm{C}$ with a relative humidity of $75 \%$. At different time intervals $(\mathrm{t}=10 \mathrm{~min}, 30 \mathrm{~min}, 1 \mathrm{~h}, 3 \mathrm{~h}$, and $6 \mathrm{~h}$ ), the content of SF in the deionized water was measured via the Bradford protein assay [69], recorded as $C$. Then, the SF/CMCS hydrogels were lyophilized and weighed, which was recorded as $m$. The percentage of SF released from the SF/CMCS hydrogel $(Q \%)$ can be calculated using the following formula, in which $n \%$ is the percentage of SF in the SF/CMCS hydrogel, determined from Formula (3):

$$
Q \%=\frac{C \times V}{(m+C \times V) \times n \%} \times 100 \%
$$

\subsection{Characterization of the Prepared SF/CMCS Hydrogel}

\subsubsection{Micromorphological Characterization}

The samples were first freeze-dried using a lyophilizer (LGJ-10, Shanghai YuMing Instrument Co., Ltd., Shanghai, China). Subsequently, the lyophilized samples were sputtercoated (GSL-1100X-SPC-16m, MTI Corporation, Richmond, VA, USA) with gold to give them a conductive coating. The surface and cross-section morphologies of SF/CMCS and CMCS hydrogels were observed using a scanning electron microscope (Phenom Pro, Phenom-World, Eindhoven, The Netherlands).

\subsubsection{Rheological Characterization}

Rheological measurements of the solutions were performed using a viscometer (DV3TLVCJ0, Brookfield, Middleboro, MA, USA) with a 48-mm-diameter parallel plate at room temperature $\left(25^{\circ} \mathrm{C}\right)$. All samples were left at rest for $5 \mathrm{~min}$ to allow for temperature equilibration.

\subsubsection{Compressive Strength Testing}

The prepared hydrogels were equilibrated in deionized water for $24 \mathrm{~h}$ to fully swell. The compressive strength was measured using a universal testing machine (Shanghai Xieqiang Instrument Technology Co., Ltd., Shanghai, China) at a test speed of $1 \mathrm{~mm} / \mathrm{min}$.

\subsubsection{Fourier-Transform Infrared Spectroscopy (FTIR) Analysis}

The freeze-dried hydrogel samples were ground into powder for attenuated total reflection Fourier transform infrared spectroscopy (ATR-FTIR) analysis (Thermo Scientific Nicolet iN10, Waltham, MA, USA) to determine their chemical/structural properties. The absorption spectra of samples in the mid-infrared region $\left(4000-400 \mathrm{~cm}^{-1}\right)$ were acquired at a resolution of $4 \mathrm{~cm}^{-1}$ and 32 scans of each sample.

\subsubsection{Thermogravimetric Analysis (TGA)}

The thermal behaviors of the samples were studied using a simultaneous thermal analyzer (STA 449 F3 Jupiter, NETZSCH, Selb, Germany). First, the samples were lyophilized and ground into powders. Then, $5 \mathrm{mg}$ of each sample was loaded in an $\mathrm{Al}_{2} \mathrm{O}_{3}$ crucible. The operation was performed from $30^{\circ} \mathrm{C}$ to $500^{\circ} \mathrm{C}$ at a constant heating rate of $10^{\circ} \mathrm{C} / \mathrm{min}$ in $\mathrm{N}_{2}$ atmosphere.

\subsubsection{Swelling Studies}

Hydrogel swelling is an important feature of wound dressings that allows hydrogel dressings to absorb wound fluids and exudates [42]. Hence, the swelling kinetics of 
SF/CMCS hydrogels at various temperatures $\left(15^{\circ} \mathrm{C}, 25^{\circ} \mathrm{C}, 37^{\circ} \mathrm{C}\right.$, and $\left.45^{\circ} \mathrm{C}\right)$ and $\mathrm{pH}$ conditions ( $\mathrm{pH}=2.1,7.4,10.0$, and 12.1) were evaluated to investigate the response of the hydrogels to different wound environments. SF/CMCS hydrogels were lyophilized and pre-weighed before immersion in a swelling medium. At specific intervals, the samples were removed from the swelling medium and weighed after the excess surface liquids were removed by blotting with Kimwipes. The swelling ratio $(S R)$ can be determined using the following equation [70]:

$$
S R=\frac{m_{s}-m_{1}}{m_{1}} \times 100 \%
$$

where $m_{s}$ is the weight of the swollen hydrogel at time $t$, and $m_{1}$ is the weight of hydrogel after lyophilization. The experiments were performed in triplicate, and the average of the results was reported with the standard deviation.

\subsubsection{Measurement of Water Vapor Transmission Rate (WVTR)}

The moisture vapor permeability of the hydrogel was described via the WVTR, assessed according to the method of the American Society for Testing and Materials (ASTM) [71]. The test was conducted at $37^{\circ} \mathrm{C}$ and with a relative humidity of $35 \%$ in an artificial environment chamber. The prepared hydrogel was used to seal the weighing bottle, containing $10 \mathrm{~mL}$ of deionized water, with the effective transfer area (recorded as $A$ ). The bottles were weighed every $12 \mathrm{~h}$ to construct a plot of the rate of water loss per unit time. Its slope was then used to determine the WVTR using the following equation [63]:

$$
\operatorname{WVTR}\left(\mathrm{g} / \mathrm{m}^{2} / \text { day }\right)=\frac{\text { slope } \times 24}{A}
$$

\subsubsection{Degradation Study In Vitro}

To investigate the stability of the hydrogel, each hydrogel was soaked in $20 \mathrm{~mL}$ of sterilized phosphate buffer solution (PBS, pH 7.4) until it reached a swelling balance. Every $24 \mathrm{~h}$, the hydrogels were removed from the immersion solution and weighed after blotting with Kimwipes. The hydrogel degradation is expressed as the percentage of mass remaining $(R M \%)$, which can be calculated according to the equation:

$$
R M \%=\frac{m_{t}}{m_{0}} \times 100 \%
$$

where $m_{0}$ is the weight of the hydrogel that achieved balance and $m_{t}$ is the weight of hydrogel at a predetermined time point.

\subsection{Antimicrobial Activity}

The antibacterial activities of the SF/CMCS and CMCS hydrogels toward Grampositive Staphylococcus aureus (S. aureus, ATCC 25923) and Gram-negative Escherichia coli (E. coli, ATCC 25922) were evaluated via the colony counting method [72]. To this end, $1.0 \mathrm{~g}$ of sterilized SF/CMCS hydrogel or CMCS hydrogel was immersed in $1.0 \mathrm{~mL}$ of Luria-Bertani (LB) broth with bacterial counts of $10^{4} \mathrm{CFU} / \mathrm{mL}$, as the experimental groups. A $1.0 \mathrm{~mL}$ aliquot of this LB broth without an immersed sample acted as the control. After $2 \mathrm{~h}$ of incubation at $37^{\circ} \mathrm{C}$, the suspension was diluted 3-fold with sterilized LB solution and then subjected to the plate counting method.

\subsection{Cytotoxicity Assay}

The degree of cytotoxicity of the SF/CMCS hydrogel was assessed by measuring the cell viability of HEK-293 cells using a Cell Counting Kit-8 (CCK-8) [73]. In short, a lyophilized sample with a weight of $0.2 \mathrm{~g}$ was submerged in $10 \mathrm{~mL}$ of Dulbecco's modified Eagle's medium (DMEM) for $72 \mathrm{~h}$ at $37^{\circ} \mathrm{C}$ to obtain its leaching liquor. HEK-293 cells were seeded in a 96-well plate with a density of $2 \times 10^{3}$ cells/well in a 100- $\mu \mathrm{L}$ suspension of complete growth medium ( $90 \%$ DMEM with $10 \%$ FBS) and were cultured for $24 \mathrm{~h}$ at $37^{\circ} \mathrm{C}$ 
in a humidified $5 \% \mathrm{CO}_{2}$ atmosphere. Then, $10 \mu \mathrm{L}$ of complete growth medium (control) or the leaching liquor of the samples was added to each well and incubated with cells for $24 \mathrm{~h}, 72 \mathrm{~h}$, and $120 \mathrm{~h}$, respectively. Subsequently, $10 \mu \mathrm{L}$ of CCK-8 was added to each well and incubated with cells for $2 \mathrm{~h}$ at $37^{\circ} \mathrm{C}$. Absorbance was measured at $450 \mathrm{~nm}$ using a microplate reader (Synergy H1, Bio-Tek, Winooski, VT, USA). The cell proliferation rate was then calculated using the following equation:

$$
\text { Cell proliferation rate }(\%)=\frac{O D_{450}(\text { sample })}{O D_{450}(\text { control })} \times 100 \%
$$

\subsection{In Vivo Wound Healing Assay}

The wound healing capacity of the SF/CMCS hydrogel was evaluated using a mouse full-thickness wound defect model. Healthy, pathogen-free female Kunming mice (purchased from Tengxin Biotechnology Co., Ltd., Chongqing, China) weighing 18-22 g were anesthetized, and a round, full-thickness wound with a diameter of $6 \mathrm{~mm}$ was created on the dorsal side of the mouse using a skin biopsy punch. The wound was covered with SF/CMCS hydrogel (SF/CMCS group), CMCS hydrogel (CMCS group), or a sterilized gauze (Sterile gauze group). The dressings were then fixed with sutures. All procedures of animal experiments were performed in compliance with the protocols approved by the Laboratory Animal Ethics Committee of Southwest University (approval code: IACUC20191215-17).

\subsubsection{Measurement of Wound Closure}

The wound size of each group was recorded using a 48-megapixel camera (Sony IMX586, Tokyo, Japan) on the 3rd, 7th, and 11th days after surgery. The area of the wound was measured using ImageJ software (1.6.0, National Institutes of Health, Bethesda, MD, USA). The degree of wound closure was calculated according to the following equation [33]:

$$
\text { Degree of wound closure }(\%)=\frac{A_{0}-A_{t}}{A_{0}} \times 100 \%
$$

where $A_{0}$ is the initial wound area on day 0 , and $A_{t}$ is the wound area on a specific day indicated after surgery.

\subsubsection{Histological Analysis of Wounds}

Hematoxylin and eosin (H\&E) staining was used for the histological analysis of wounds. Once the mice were euthanized, the wound tissue was excised and bisected. The skin wound tissue specimens were then fixed in 10\% neutral-buffered formalin solution and embedded in paraffin. The tissue blocks were serially sectioned perpendicular to the skin surface at a 5- $\mu$ m thickness, followed by H\&E staining for histological analysis [74].

\subsection{Statistical Analysis}

All values are reported as the mean \pm standard deviation for at least three replicates. Statistical analyses were performed using an unpaired, two-tailed $t$-test $\left({ }^{*} p<0.05,{ }^{* *} p<0.01\right)$.

\section{Conclusions}

In summary, relying on the electrodeposition technique, we developed an easy, green, controllable, and low-voltage approach to SF-based hydrogel fabrication by exploiting intermolecular hydrogen bonding between SF and CMCS. The prepared SF/CMCS hydrogel featured a porous architecture, $\mathrm{pH}$ - and temperature-sensitive equilibrium swelling behavior, antibacterial activity, and was shown to improve cell growth. According to an in vivo assessment of a full-thickness skin defect model in mice, the SF/CMCS hydrogel exhibited prominent wound healing efficiency with respect to wound re-epithelization and granulation tissue formation. These findings have significant implications for the 
feasibility of the developed implementation strategy for SF-based hydrogel preparation and its application as a wound dressing.

Supplementary Materials: The following are available online at https:/ /www.mdpi.com/article/10 $.3390 / \mathrm{ijms} 22147610 / \mathrm{s} 1$.

Author Contributions: Conceptualization, Z.C. and X.Z.; methodology, Z.C. and X.Z.; software, J.L. and Y.J.; validation, Z.C., J.L., Y.Z. and H.F.; formal analysis, Z.C.; funding acquisition, X.Z.; investigation, Z.C., J.L. and Y.J.; resources, Z.C. and X.Z.; data curation, Z.C. and X.Z.; writingoriginal draft preparation, X.Z. and Z.C.; writing-review and editing, Z.C. and X.Z.; visualization, Z.C., J.L., Y.J. and Y.Z.; supervision, X.Z.; project administration, X.Z. All authors have read and agreed to the published version of the manuscript.

Funding: This research was funded by the Fundamental Research Funds for the Central Universities (grant number SWU117036); Chongqing Municipal Training Program of Innovation and Entrepreneurship for Undergraduates (grant number S202110635037); Venture and Innovation Support Program for Chongqing Overseas Returnees (grant number cx2019098).

Institutional Review Board Statement: All procedures of animal experiments were performed in compliance with the protocols approved by the Laboratory Animal Ethics Committee of Southwest University (approval code: IACUC-20191215-17).

Informed Consent Statement: Not applicable.

Data Availability Statement: The data presented in this study are available on request from the corresponding author.

Conflicts of Interest: The authors declare no conflict of interest.

\section{References}

1. Yang, N.; Qi, P.; Ren, J.; Yu, H.; Ling, S. Polyvinyl alcohol/silk fibroin/borax hydrogel ionotronics: A highly stretchable, self-healable, and biocompatible sensing platform. ACS Appl. Mater. Interfaces 2019, 11, 23632-23638. [CrossRef]

2. Grant, A.M.; Kim, H.S.; Dupnock, T.L.; Hu, K.; Yingling, Y.G.; Tsukruk, V.V. Silk fibroin-substrate interactions at heterogeneous nanocomposite interfaces. Adv. Funct. Mater 2016, 26, 6380-6392. [CrossRef]

3. Wang, J.; Yang, Q.; Cheng, N.; Tao, X.; Zhang, Q. Collagen/silk fibroin composite scaffold incorporated with PLGA microsphere for cartilage repair. Mat. Sci. Eng. C 2016, 61, 705-711. [CrossRef] [PubMed]

4. Rnjak-Kovacina, J.; Desrochers, T.M.; Burke, K.A.; Kaplan, D.L. The effect of sterilization on silk fibroin biomaterial properties. Macromol. Biosci. 2015, 15, 861-874. [CrossRef] [PubMed]

5. Sun, W.; Incitti, T.; Migliaresi, C.; Quattrone, A.; Casarosa, S.; Motta, A. Viability and neuronal differentiation of neural stem cells encapsulated in silk fibroin hydrogel functionalized with an IKVAV peptide. J. Tissue Eng. Regener. Med. 2017, 11, 1532-1541. [CrossRef] [PubMed]

6. Zhao, L.; Wang, H.; Luo, J.; Cai, C.; Song, G.L.; Tang, G.Y. Fabrication of silk fibroin film with properties of thermal insulation and temperature monitoring. J. Polym. Sci. Part B Polym. Phys. 2016, 54, 1846-1852. [CrossRef]

7. Mao, K.L.; Fan, Z.L.; Yuan, J.D.; Chen, P.P.; Yang, J.J.; Xu, J.; Zhuge, D.L.; Jin, B.H.; Zhu, Q.Y.; Shen, B.X. Skin-penetrating polymeric nanoparticles incorporated in silk fibroin hydrogel for topical delivery of curcumin to improve its therapeutic effect on psoriasis mouse model. Colloids Surf. B 2017, 160, 704-714. [CrossRef]

8. Yoo, M.K.; Kweon, H.Y.; Lee, K.G.; Lee, H.C.; Cho, C.S. Preparation of semi-interpenetrating polymer networks composed of silk fibroin and poloxamer macromer. Int. J. Biol. Macromol. 2004, 34, 263-270. [CrossRef]

9. Das, S.; Pati, F.; Choi, Y.J.; Rijal, G.; Shim, J.H.; Kim, S.W.; Ray, A.R.; Cho, D.W.; Ghosh, S. Bioprintable, cell-laden silk fibroingelatin hydrogel supporting multilineage differentiation of stem cells for fabrication of three-dimensional tissue constructs. Acta Biomater. 2015, 11, 233-246. [CrossRef] [PubMed]

10. Wang, S.D.; Zhang, K.Q. Electrogelation and rapid prototyping of Bombyx mori silk fibroin. Mater. Lett. 2016, 169, 5-9. [CrossRef]

11. Wang, X.; Kluge, J.A.; Leisk, G.G.; Kaplan, D.L. Sonication-induced gelation of silk fibroin for cell encapsulation. Biomaterials 2008, 29, 1054-1064. [CrossRef]

12. Cheng, X.; Deng, D.; Chen, L.; Jansen, J.A.; Yang, F. Electrodeposited assembly of additive-free silk fibroin coating from pre-assembled nanospheres for drug delivery. ACS Appl. Mater. Interfaces 2020, 12, 12018-12029. [CrossRef]

13. Lu, Q.; Huang, Y.; Li, M.; Zuo, B.; Lu, S.; Wang, J.; Zhu, H.; Kaplan, D.L. Silk fibroin electrogelation mechanisms. Acta Biomater. 2011, 7, 2394-2400. [CrossRef] [PubMed]

14. Nelson, D.L.; Cox, M.M. Lehninger Principles of Biochemistry; W.H. Freeman: New York, NY, USA, 2017.

15. Pan, J.; Zhang, Z.; Zhan, Z.; Xiong, Y.; Chen, Y. In situ generation of silver nanoparticles and nanocomposite films based on electrodeposition of carboxylated chitosan. Carbohydr. Polym. 2020, 242, 116391. [CrossRef] [PubMed] 
16. Geng, Z.; Wang, X.; Guo, X.; Zhang, Z.; Chen, Y.; Wang, Y. Electrodeposition of chitosan based on coordination with metal ions in situ-generated by electrochemical oxidation. J. Mater. Chem. B 2016, 4, 3331-3338. [CrossRef]

17. Wu, L.Q.; Gadre, A.P.; Yi, H.M.; Kastantin, M.J.; Ghodssi, R. Voltage-dependent assembly of the polysaccharide chitosan onto an electrode surface. Langmuir 2010, 18, 8620-8625. [CrossRef]

18. Oliveira, J.A.M.; Santana, R.A.C.D.; Neto, A.D.O.W. Characterization of the chitosan-tungsten composite coating obtained by electrophoretic deposition. Prog. Org. Coat. 2020, 143, 105631-105641. [CrossRef]

19. Kim, E.; Xiong, Y.; Cheng, Y.; Wu, H.C.; Liu, Y.; Morrow, B.H.; Ben-Yoav, H.; Ghodssi, R.; Rubloff, G.W.; Shen, J.; et al. Chitosan to connect biology to electronics: Fabricating the bio-device interface and communicating across this interface. Polymers 2015, 7, 1-46. [CrossRef]

20. Wang, W.; Hu, J.; Zhang, R.; Yan, C.; Zhu, J. A pH-responsive carboxymethyl cellulose/chitosan hydrogel for adsorption and desorption of anionic and cationic dyes. Cellulose 2020, 28, 897-909. [CrossRef]

21. Hao, X.; Wang, X.; Yang, W.; Ran, J.; Ni, F.; Tong, T.; Dai, W.; Zheng, L.; Shen, X.; Tong, H. Comparisons of the restoring and reinforcement effects of carboxymethyl chitosan-silk fibroin (Bombyx Mori/Antheraea Yamamai/Tussah) on aged historic silk Int. J. Biol. Macromol. 2018, 124, 71-79. [CrossRef]

22. Fawal, G.; Abu-Serie, M.M.; Hassan, M.A.; Elnouby, M.S. Hydroxyethyl cellulose hydrogel for wound dressing: Fabrication, characterization and in vitro evaluation. Int. J. Biol. Macromol. 2018, 111, 649-659. [CrossRef]

23. Thet, N.T.; Alves, D.R.; Bean, J.E.; Booth, S.; Jenkins, A. Prototype development of the intelligent hydrogel wound dressing and its efficacy in the detection of model pathogenic wound biofilms. ACS Appl. Mater. Interfaces 2016, 8, 14909-14919. [CrossRef] [PubMed]

24. Yan, K.; Liu, Y.; Zhang, J.; Correa, S.O.; Payne, G.F. Electrical programming of soft matter: Using temporally varying electrical inputs to spatially control self assembly. Biomacromolecules 2017, 19, 364-373. [CrossRef]

25. Motta, A.; Fambri, L.; Migliaresi, C. Regenerated silk fibroin films: Thermal and dynamic mechanical analysis. Macromol. Chem. Phys. 2002, 203, 1658-1665. [CrossRef]

26. Kaya, M.; Cakmak, Y.S.; Baran, T.; Asan-Ozusaglam, M.; Mentes, A.; Tozak, K.O. New chitin, chitosan, and O-carboxymethyl chitosan sources from resting eggs of Daphnia longispina (Crustacea); with physicochemical characterization, and antimicrobial and antioxidant activities. Biotechnol. Bioproc. E 2014, 19, 58-69. [CrossRef]

27. Dhivya, S.; Padma, V.V.; Santhini, E. Wound dressings-A review. Biomedicine 2015, 5, 24-28. [CrossRef]

28. Veld, R.; Walboomers, X.F.; Jansen, J.A.; Wagener, F. Design considerations for hydrogel wound dressings: Strategic and molecular advances. Tissue Eng. Part B 2020, 26, 230-248. [CrossRef]

29. Kluin, O.S.; Van, D.; Busscher, H.J.; Neut, D.L. Biodegradable vs non-biodegradable antibiotic delivery devices in the treatment of osteomyelitis. Expert Opin. Drug Deliv. 2013, 10, 341-351. [CrossRef] [PubMed]

30. Jiang, X.; Lu, C.; Tang, M.; Yang, Z.; Jia, W.; Ma, Y.; Jia, P.; Pei, D.; Wang, H. Nanotoxicity of silver nanoparticles on HEK293T cells: A combined study using biomechanical and biological techniques. ACS Omega 2018, 3, 6770-6778. [CrossRef] [PubMed]

31. Kouser, R.; Vashist, A.; Zafaryab, M.; Rizvi, M.A.; Ahmad, S. Biocompatible and mechanically robust nanocomposite hydrogels for potential applications in tissue engineering. Mater. Sci. Eng. C 2018, 84, 168-179. [CrossRef]

32. Reyes-Esparza, J.; Martínez-Mena, A.; Gutiérrez-Sancha, I.; Rodríguez-Fragoso, P.; Rodríguez-Fragoso, L. Synthesis, characterization and biocompatibility of cadmium sulfide nanoparticles capped with dextrin for in vivo and in vitro imaging application. $J$. Nanobiotechnol. 2015, 13, 83-96. [CrossRef]

33. Fan, Z.J.; Liu, B.; Wang, J.Q.; Zhang, S.Y.; Lin, Q.Q.; Gong, P.W.; Ma, L.M.; Yang, S.G. A novel wound dressing based on $\mathrm{Ag}$ /graphene polymer hydrogel: Effectively kill bacteria and accelerate wound healing. Adv. Funct. Mater. 2014, 24, 3933-3943. [CrossRef]

34. Jin, Q.; Xin, Z.; Yongping, L.; Tianlong, Z.; Ma, P.X.; Baolin, G. Antibacterial adhesive injectable hydrogels with rapid self-healing, extensibility and compressibility as wound dressing for joints skin wound healing. Biomaterials 2018, 183, 185-199. [CrossRef]

35. Laliberté, M. Model for calculating the viscosity of aqueous solutions. J. Chem. Eng. Data 2007, 52, 321-335. [CrossRef]

36. Kalliola, S.; Repo, E.; Srivastava, V.; Zhao, F.; Heiskanen, J.P.; Sirvi, J.A.; Liimatainen, H.; Sillanp, M. Carboxymethyl chitosan and its hydrophobically modified derivative as pH-switchable emulsifiers. Langmuir 2018, 34, 2800-2806. [CrossRef] [PubMed]

37. Guziewicz, N.A.; Massetti, A.J.; Perez-Ramirez, B.J.; Kaplan, D.L. Mechanisms of monoclonal antibody stabilization and release from silk biomaterials. Biomaterials 2013, 34, 7766-7775. [CrossRef]

38. Luckham, P.; Zhu, S. The effects of hydrogen bonding upon the viscosity of aqueous poly(vinyl alcohol) solutions. Polymer 2000, 41, 3851-3860. [CrossRef]

39. Ma, Y.; Liu, Y.; Su, H.; Wang, L.; Zhang, J. Relationship between hydrogen bond and viscosity for a series of pyridinium ionic liquids: Molecular dynamics and quantum chemistry. J. Mol. Liq. 2018, 255, 176-184. [CrossRef]

40. Kabiri, K.; Zohuriaan-Mehr, M.J. Superabsorbent hydrogel composites. Polym. Adv. Technol. 2003, 14, 438-444. [CrossRef]

41. Zhou, W.; Yuan, S.; Chen, Y.; Bao, L. Morphology and hydrogen-bond restricted crystallization of poly(butylene succinate)/cellulose diacetate blends. J. Appl. Polym. Sci. 2012, 124, 3124-3131. [CrossRef]

42. Mohamad, N.; Amin, M.C.I.M.; Pandey, M.; Ahmad, N.; Rajab, N.F. Bacterial cellulose/acrylic acid hydrogel synthesized via electron beam irradiation: Accelerated burn wound healing in an animal model. Carbohydr. Polym. 2014, 114, 312-320. [CrossRef]

43. Ono, S.; Imai, R.; Ida, Y.; Shibata, D.; Komiya, T.; Matsumura, H. Increased wound pH as an indicator of local wound infection in second degree burns. Burns 2015, 41, 820-824. [CrossRef] [PubMed] 
44. Li, X.; Xu, S.; Wang, J.; Chen, X.; Feng, S. Structure and characterization of amphoteric semi-IPN hydrogel based on cationic starch. Carbohydr. Polym. 2009, 75, 688-693. [CrossRef]

45. Chen, T.; Liu, H.; Dong, C.; An, Y.; Zhang, M. Synthesis and characterization of temperature/pH dual sensitive hemicellulosebased hydrogels from eucalyptus APMP waste liquor. Carbohydr. Polym. 2020, 247, 116717. [CrossRef] [PubMed]

46. Nuisin, R.; Kiatkamjornwong, S. Graft copolymerization, characterization, and degradation of cassava starch-g-acrylamide/itaconic acid superabsorbents. Carbohydr. Polym. 2006, 66, 229-245. [CrossRef]

47. Queen, D.; Gaylor, J.D.S.; Evans, J.H.; Courtney, J.M.; Reid, W.H. The preclinical evaluation of the water vapour transmission rate through burn wound dressings. Biomaterials 1987, 8, 367-371. [CrossRef]

48. Li, G.M.; Feng, C.; Li, J.F.; Liu, J.Z.; Wu, Y.L. Water vapor permeation and compressed air dehydration performances of modified polyimide membrane. Sep. Purif. Technol. 2008, 60, 330-334. [CrossRef]

49. Williams, R.W.; Mason, L.B.; Bradshaw, H.H. Factors affecting wound healing. Surg. Forum. 1950, 17, 410-417. [CrossRef]

50. Ahmed, I.; Istivan, T.; Pirogova, E. The effect of extremely low frequency (ELF) pulsed electromagnetic field (PEMF) on bacteria staphylococcus aureus. In Proceedings of the Progress in Electromagnetics Research Symposium 2013, Taipei, Taiwan, 25-28 March 2013; pp. 388-391.

51. Cheng, L.; Cai, Z.; Ye, T.; Yu, X.; Chen, Z.; Yan, Y.; Qi, J.; Wang, L.; Liu, Z.; Cui, W.; et al. Injectable polypeptide—Protein hydrogels for promoting infected wound healing. Adv. Funct. Mater. 2020, 30, 2001196. [CrossRef]

52. Huang, Y.; Shi, F.; Wang, L.; Yang, Y.; Khan, B.M.; Cheong, K.L.; Liu, Y. Preparation and evaluation of Bletilla striata polysaccharide/carboxymethyl chitosan/Carbomer 940 hydrogel for wound healing. Int. J. Biol. Macromol. 2019, 1, 729-737. [CrossRef]

53. Shi, C.; Pu, X.; Zheng, G.; Feng, X.; Yang, X.; Zhang, B.; Zhang, Y.; Yin, Q.; Xia, H. An antibacterial and absorbable silk-based fixation material with impressive mechanical properties and biocompatibility. Sci. Rep. 2016, 21, 37418-37430. [CrossRef] [PubMed]

54. Zhang, X.; Bao, H.; Donley, C.; Liang, J.; Xu, S. Thiolation and characterization of regenerated Bombyx mori silk fibroin films with reduced glutathione. BMC. Chem. 2019, 13, 62-71. [CrossRef] [PubMed]

55. Li, D.W.; Lei, X.; He, F.L.; He, J.; Liu, Y.L.; Ye, Y.J.; Deng, X.; Duan, E.; Yin, D.C. Silk fibroin/chitosan scaffold with tunable properties and low inflammatory response assists the differentiation of bone marrow mesenchymal stem cells. Int. J. Biol. Macromol. 2017, 105, 584-597. [CrossRef]

56. Hersel, U.; Dahmen, C.; Kessler, H. RGD modified polymers: Biomaterials for stimulated cell adhesion and beyond. Biomaterials 2003, 24, 4385-4415. [CrossRef]

57. Schreml, S.; Szeimies, R.M.; Prantl, L.; Landthaler, M.; Babilas, P. Wound healing in the 21st century. J. Am. Acad. Dermatol. 2010, 63, 866-881. [CrossRef]

58. Wang, Y.Z.; Xu, R.; Luo, G.X.; Lei, Q.; Shu, Q.; Yao, Z.H.; Li, H.S.; Zhou, J.Y.; Tan, J.G.; Yang, S.S.; et al. Biomimetic fibroblast-loaded artificial dermis with "sandwich" structure and designed gradient pore sizes promotes wound healing by favoring granulation tissue formation and wound re-epithelialization. Acta Biomater. 2016, 30, 246-257. [CrossRef] [PubMed]

59. Xu, R.; Luo, G.X.; Xia, H.H.; He, W.F.; Zhao, J.; Liu, B.; Tan, J.L.; Zhou, J.Y.; Liu, D.S.; Wang, Y.Z.; et al. Novel bilayer wound dressing composed of silicone rubber with particular micropores enhanced wound re-epithelialization and contraction. Biomaterials 2015, 40, 1-11. [CrossRef]

60. Gültekin, S.E.; Sengüven, B.; SofuoğLu, A.; Taner, L.; Koch, M. Effect of the topical use of the antioxidant taurine on the two basement membrane proteins of regenerating oral gingival epithelium. J. Periodontol. 2012, 83, 127-134. [CrossRef]

61. Clark, R.A.F.; Singer, A.J. Wound Repair: Basic Biology to Tissue Engineering; Academic Press: Amsterdam, The Netherlands, 2014.

62. Jones, K. Fibrotic response to biomaterials and all associated sequence of fibrosis. In Host Response to Biomaterials; Academic Press: Amsterdam, The Netherlands, 2015; pp. 189-237. [CrossRef]

63. Balakrishnan, B.; Mohanty, M.; Umashankar, P.R.; Jayakrishnan, A. Evaluation of an in situ forming hydrogel wound dressing based on oxidized alginate and gelatin. Biomaterials 2005, 26, 6335-6342. [CrossRef]

64. Bush, K.; Gertzman, A.A. Process Development and Manufacturing of Human and Animal Acellular Dermal Matrices. In Skin Tissue Engineering and Regenerative Medicine; Academic Press: Amsterdam, The Netherlands, 2016.

65. Abbas, A.; Aster, J.; Kumar, V. Robbins Basic Pathology, 10th ed.; Peking University Medical Press: Beijing, China, 2018.

66. Chouhan, D.; Lohe, T.U.; Samudrala, P.K.; Mandal, B.B. In situ forming injectable silk fibroin hydrogel promotes skin regeneration in full thickness burn wounds. Adv. Healthc. Mater. 2018, 7, 1801092-1801107. [CrossRef]

67. Muzzarelli, R.A.A.; Tanfani, F.; Emanuelli, M.; Mariotti, S. N-(carboxymethylidene)chitosans and N-(carboxymethyl)chitosans: Novel chelating polyampholytes obtained from chitosan glyoxylate. Carbohydr. Res. 1982, 107, 199-214. [CrossRef]

68. Cai, J.; Zhang, L.N.; Chang, C.Y.; Cheng, G.Z.; Chen, X.M. Hydrogen-bond-induced inclusion complex in aqueous cellulose/LiOH/urea solution at low temperature. Chemphyschem 2007, 8, 1572-1579. [CrossRef] [PubMed]

69. Aneesia, V.; Elakkiya, V.; Ponjanani, S.; Gopinathan, J.; Amitava, B. Impact of silk fibroin-based scaffold structures on human osteoblast MG63 cell attachment and proliferation. Int. J. Nanomed. 2015, 10, 43-51. [CrossRef]

70. Ariaeenejad, S.; Hosseini, E.; Motamedi, E.; Moosavi-Movahedi, A.A.; Salekdeh, G.H. Application of carboxymethyl cellulosepoly(acrylic acid-acrylamide) hydrogel sponges for improvement of efficiency, reusability and thermal stability of a recombinant xylanase. Chem. Eng. J. (Lausanne) 2019, 375, e122022. [CrossRef] 
71. Hong, P.; Daidi, F.; Wei, C.; Chenhui, Z.; Zhiguang, D.; Rongzhan, F.; Xian, L.; Xiaoxuan, M. Preparation and characterization of breathable hemostatic hydrogel dressings and determination of their effects on full-thickness defects. Polymers 2017, 9, 727. [CrossRef]

72. Marslin, G.; Selvakesavan, R.K.; Franklin, G.; Sarmento, B.; Dias, A.C. Antimicrobial activity of cream incorporated with silver nanoparticles biosynthesized from Withania somnifera. Int. J. Nanomed. 2015, 2015, 5955-5963. [CrossRef]

73. Tang, Z.; Jiang, F.; Zhang, Y.; Zhang, Y.; Huang, X.; Wang, Y.; Zhang, D.; Ni, N.; Liu, F.; Luo, M.; et al. Mussel-inspired injectable hydrogel and its counterpart for actuating proliferation and neuronal differentiation of retinal progenitor cells. Biomaterials 2018, 194, 57-72. [CrossRef]

74. Chen, G.; Yu, Y.; Wu, X.; Wang, G.; Ren, J.; Zhao, Y. Bioinspired multifunctional hybrid hydrogel promotes wound healing. Adv. Funct. Mater. 2018, 28, 1801386-1801396. [CrossRef] 